\title{
Los Reyes Católicos en la pintura española del siglo XIX
}

\author{
Wifredo Rincón García
}

Arbor CLXXVIII, 701 (Mayo 2004), 129-161 pp.

A lo largo del siglo XIX, uno de los temas históricos más recurrentes de la pintura española será el reinado de los Reyes Católicos y los artistas se sucederán a lo largo del siglo plasmando los más diversos momentos de la vida y el gobierno de Isabel I de Castilla y Fernando II de Aragón que, tras unir sus vidas y sus coronas, unificaron también los reinos hispánicos y juntos culminaron en 1492 la larga tarea de la reconquista iniciada muchos siglos antes. Durante su reinado tuvo lugar también el Descubrimiento de América, sin lugar a dudas, otro de los hitos históricos más importantes de la pintura española y en cuya iconografía estos monarcas juegan también un papel importante.

Sin embargo, el interés de los pintores por la figura de los Reyes Católicos no sólo es un fenómeno decimonónico, pues desde mediados del siglo XVIII hay una serie de pinturas que los representan, tanto en frescos que decoran los palacios reales, como en lienzos, pues las Reales Acade mias de Bellas Artes en muchas ocasiones propondrán como tema para sus premios páginas de la historia de estos monarcas y así ocurre por ejemplo, en los premios de primera clase de pintura de 1790, cuando se propuso «Los Reyes Católicos D. Fernando y doña Isabel reciben a los Embajadores, que el Rey de Fez les envía con un rico presente de caballos, jaeces, telas, y otras cosas para solicitar su amistad y buena correspondencia que dichos soberanos admitieron, con tal que no socorriesen el rey de Granada». Una pintura con este tema, con la que ganó Vicente López (Valencia, 1772-Madrid, 1850) el primer premio, titulada Los Reyes Católicos recibiendo a una embajada de Fez, se conserva en el Museo de la Real Academia de Bellas Artes de San Fernando en Madrid ${ }^{1}$. 
Tras la guerra de la Independencia, los temas de la historia española tendrán una importante vigencia, pero será con el romanticismo, coincidente con el reinado de Isabel II, cuando estas páginas del reinado de Isabel y Fernando tendrán un mayor desarrollo en nuestras artes. La figura de la reina española se pondrá en paralelo a su reina homónima, Isabel la Católica y en muchas ocasiones en los programas iconográficos proyectados para la decoración de algunos edificios singulares, se representaran las dos «Isabeles» y así ocurre, por ejemplo, en dos de las pinturas que cubren la bóvedas del Paraninfo de la Universidad Complutense de Madrid, levantado en la antigua iglesia del Noviciado de los Jesuitas, en la madrileña calle de San Bernardo, ejecutadas por Joaquín Espalter entre 1854 y 1858. En la cabecera fue representada la reina Isabel II, mientras que en los pies, sobre la inscripción conmemorativa de su inauguración, aparece la reina Isabel I, sedente en un trono, con cetro y corona, y rodeada de algunos elementos alegóricos.

Este mismo sentido debemos darle a otra pintura de Vicente López, grabada por Ramón Amérigo y Morales (Alicante, 1807 - Madrid, 1884) en la Real Litografía de Madrid. Representa a la Reina Isabel la Católica que lleva de la mano izquierda a la reina Isabel II, niña, mientras que levanta su brazo derecho, con el cetro, hacia una montaña donde se encuentra un templo de planta circular. Al lado de la reina castellana un león que avanza junto con las dos mujeres. El texto que figura en la lámina completa el sentido de la imagen: «La Catolica Reyna, cuya historia llena de noble orgullo al pueblo íbero, Guia a su nieta al templo de la gloria ${ }^{2}$.

Con la creación de las Exposiciones Nacionales de Bellas Artes por Isabel II en 1852, cuya primera muestra tuvo lugar en 1856, la pintura de historia proliferará, premiándose muchos lienzos que representaban momentos del reinado de los Reyes Católicos, temática esta que será constante a lo largo de toda la segunda mitad del siglo y que aún se prolongó en los primeros años del siglo $\mathrm{XX}^{3}$.

Y a propósito de los cuadros de historia, recordaremos algunas de las características que debían de reunir estas obras, destacando entre ellas que los lienzos debían ser grandes, aparatosamente grandes, coloristas y con numerosas figuras, debiéndose prestar importante atención al tema, pues como publicaba en su Manual del pintor de Historia el profesor de la Escuela de Bellas Artes de San Fernando don Francisco de Mendoza: «debe meditarse mucho sobre la elección del asunto para que tenga interés, y el público ilustrado lo comprenda en el acto, y sea una página de la historia que recuerde un hecho notable bajo cualquier concepto que 


\section{Los Reyes Católicos en la pintura española del siglo XIX}

sea; por bien ejecutado que esté, si el asunto no tiene interés, rebaja infinito el mérito de la obra ${ }^{4}$.

\section{Isabel de Trastámara: el camino hacia el trono de Castilla}

Cuando nació la infanta doña Isabel, hija del rey Juan II de Castilla y de su segunda mujer la reina Isabel de Portugal, en Madrigal de las Altas Torres (Avila) en 1451, sus derechos al trono eran hipotéticos. Sin embargo, un conjunto de circunstancias le dieron, años más tarde, la corona de Castilla.

Los biógrafos de doña Isabel nos han proporcionado un retrato físico de la soberana que en muchas ocasiones ha sido tenido en cuenta por los pintores para sus obras, destacando de él que la reina era alta, rubia, un tanto gruesa, como una campesina, y de piel blanca lechosa, como todos los Trastámara. A este retrato hay que sumar los retratos que de ella se conservan, tanto en escultura como en pintura, que fueron objeto, sin lugar a dudas, de estudio por los artistas antes de ejecutar sus obras.

Tras la muerte del rey Juan II de Castilla en 1454, la reina doña Isabel trasladó su residencia a Arévalo, villa que le había legado el monarca, y en este lugar transcurrió su vida hasta hasta su fallecimiento en agosto de 1496 y con ella, quien ya comenzaba a presentar los primeros síntomas de locura, transcurrieron los primeros años de la vida de los infantes doña Isabel y don Alfonso. Este momento es el representado por el pintor nazareno catalán Pelegrín Clavé (1811-1880) en un cuadro que se conserva en el Museo de la Academia de Bellas Artes de San Carlos de México, de 288 × $226 \mathrm{~cm}$, expuesto en la octava Exposición de la Academia de San Carlos de México en 1855, institución de la que Clavé era Director desde diez años antes. Díez, describe así el cuadro: «Así, la reina está sentada en un trono con dosel, adornado con el escudo de Castilla sujeto por leones rampantes. Abandonada sobre un grueso almohadón y con la mirada de sus ojos grandes absolutamente extraviada en el vacío, no reacciona ante las caricias compasivas de sus dos hijos, que se refugian en su regazo con una profunda tristeza reflejada en sus rostros. La joven Isabel, vestida con un traje de raso, está arrodillada junto a su madre, apoyando sobre su pechos las manos mientras que el pequeño infante don Alfonso, vestido con jubón de terciopelo y calzas, apoya la cabeza sobre el hombro de la reina, cogiéndole la mano en un gesto de ternura filial. Recostada al otro lado del trono, la fiel Beatriz de Bobadilla se cubre el rostro con la mano para ocultar su dolor... El anciano Cibdarreal, médico de la reina, contempla con resignada impotencia tan patética escena.... ${ }^{5}$ (Fig. 1). 


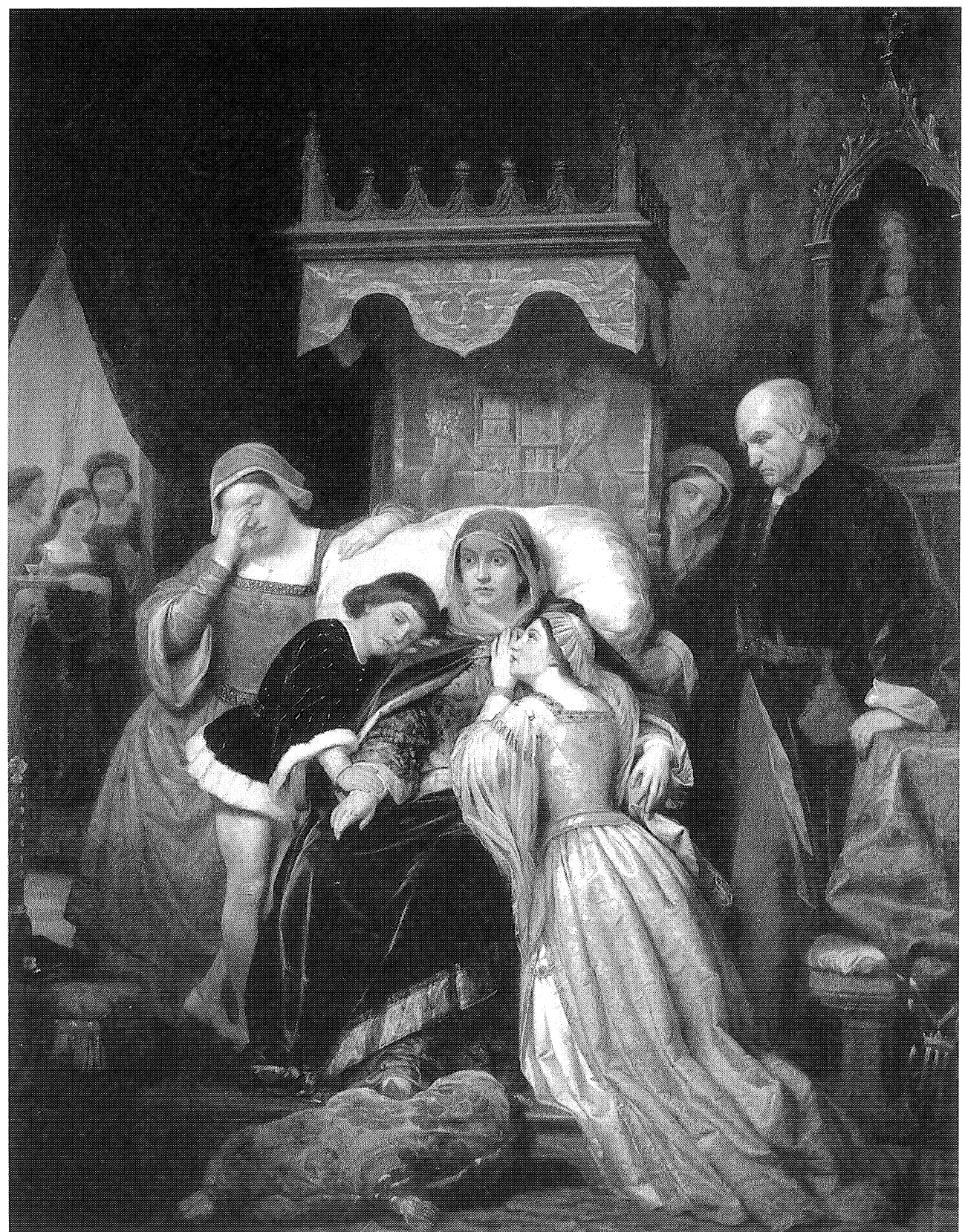

Fig. 1. Pelegrín Clavé, La demencia de Isabel de Portugal (primera juventud de Isabel la Católica al lado de su enferma madre), México, Museo de la Academia de Bellas Artes de San Carlos. 
Los Reyes Católicos en la pintura española del siglo XIX

Muy pronto el rey Enrique IV llevó a sus hermanastros Isabel y Alfonso (nacido en Tordesillas en 1543) a la corte de Segovia, pues la joven infanta podía ser una pieza decisiva para sus intereses y primero pensó en casarla con el rey Alfonso V de Portugal, pero más tarde el juego de las banderías aconsejó que diese su mano a don Pedro Girón, maestre de Calatrava, hombre viciosos y brutal que, por fortuna para Isabel, murió cuando marchaba a Segovia. Sin embargo, la corte de Enrique IV no era un lugar agradable, pues a la corrupción de las costumbres se unían los odios y ambiciones de los nobles que no vacilaron en utilizar al infante don Alfonso como bandera para disfrazar su rebeldía con la defensa de una causa justa. Gran parte de la nobleza castellana envió a Enrique IV un manifiesto en el que se le acusaba, entre otras cosas, de haber dado a don Beltrán de la Cueva el Maestrazgo de la Orden de Santiago, cuya administración había sido concedida por Juan II, a la muerte de don Alvaro de Luna, al infante don Alfonso y se exigía para este también su reconocimiento como príncipe heredero, pues doña Juana la Beltraneja, «no era su hija ni como legítima podía sucederle después de sus días».

En los Pactos de Cabezón de 1464 accedió Enrique IV a lo que se le pedía, pero más tarde se retractó de lo hecho, llevándose entonces a cabo por la nobleza la deposición de Avila (1465) en la que Alfonso era proclamado rey. Castilla se enfrentó entonces a una guerra civil en la que fueron definitivas la batalla de Olmedo y la toma de Segovia por los partidarios de don Alfonso que, fatalmente, moría inesperadamente el 5 de julio de 1468 en Cardeñosa, aldea de Ávila. Fue enterrado en la iglesia de San Francisco de Arévalo y más tarde fue trasladado a la cartuja de Miraflores, donde yace con sus padres.

Muerto el infante don Alfonso, sus partidarios quisieron proclamar reina a doña Isabel, pero esta se negó a actuar en contra de su hermano Enrique IV y, refugiada en el convento de Santa Ana, en Ávila, procuró un acuerdo con él, manteniendo su reivindicación como heredera de la corona castellano por lo que se pactaban las rentas convenientes a su rango; la convocatoria de Cortes para sancionar su derecho sucesorio; que no sería obligada a casarse contra su voluntad, que ella no contraería matrimonio sin el consentimiento de su hermano y que doña Juana, la Beltraneja, se separaría de su marido. Como consecuencia de este convenio Enrique e Isabel se entrevistaron cordialmente el 18 de septiembre de 1468 en los Toros de Guisando, a mitad de camino entre Ávila y Madrid.

Tras este tratado y proclamada ya Isabel princesa heredera, hizo su entrada triunfal en Segovia guiada por su hermano Enrique IV, tema 
este que fue objeto de atención por algunos pintores españoles ya desde la segunda mitad del siglo XVIII, pues en la convocatoria de los Premios de la Real Academia de Bellas Artes de San Fernando para 1769 se propuso para la prueba de pensado de la segunda clase de pintura el siguiente asunto: «El rey Don Enrique IV. Conduce á su hermana la Princesa Doña Isabel por las calles de Segovia á cavallo, llevando el Rey las riendas, y á las puertas de Palacio la recive el Príncipe Don Fernando de Aragón su Esposo». Participaron José Le Greslier, Manuel de la Cruz, Tomás Medina, Lino García, Miguel Lores, Félix Rodríguez y Antonio Media y una vez que fueron confrontadas las pruebas de pensado con las de repente se concedió el primer premio al dibujo de Manuel de la Cruz y el segundo premio a Félix Rodríguez. Ambas obras se conservan en el Museo de la Real Academia de Bellas Artes de San Fernando (Inv. núms. $1560 / \mathrm{P}$ y $1561 / \mathrm{P})^{6}$.

Los opositores debieron recurrir al siguiente texto de la Historia de Segovia, de Colmenares: «El siguiente dia la Princesa en un palafrán, que el mismo Rey llevó de la rienda para mas favor paseó nuestra Ciudad: Olvidando nuestros Ciudadanos, alegres con tal acción, cuantos desasosiegos avian padecido los dias y años pasados. Quando el acompañamiento bolbio a palacio hallaron en el al Principe, que salio a recibir al Rey cuñado a las puertas...» ${ }^{7}$, el mismo que figura en el Catálogo, de la Exposición Nacional de Bellas Artes de 1862 acompañando la ficha del cuadro presentado por el pintor Juan García Martínez (Calatayud, Zaragoza, 1829 - Madrid, 1895) y titulado: Manifestación del rey Don Enrique IV de Castilla al pueblo segoviano (cat. 101, p. 21). El cuadro, de $331 \mathrm{x}$ $284 \mathrm{~cm}$, que obtuvo mención honorífica, se encuentra depositado desde 1875 en el Museo de Gerona.

Pronto surgió un problema, pues mientras que los adictos a Isabel trataban de concertar la boda de ésta con el príncipe heredero de Aragón, Fernando, el monarca Enrique IV negociaba una doble boda: la del rey Alfonso V de Portugal con Isabel y la de Juan, hijo del monarca portugués con la Beltraneja. Isabel, que dudaba entre la fidelidad debida a su hermano y lo que ya consideraba sus propios intereses, tuvo también noticia de que Luis XI de Francia enviaba una embajada con la propuesta de casarla con el duque de Guyena. Entonces se decidió por el príncipe aragonés, por lo que el arzobispo Carrillo y el almirante don Fradique Enriquez arreglaron los detalles y Fernando viajó hacia Castilla disfrazado de mozo de mulas, mientras Isabel buscaba refugio en Valladolid. Tras su encuentro en el palacio de los Vivero, contrajeran matrimonio el 19 de octubre de 1469, después que el arzobispo to- 
Los Reyes Católicos en la pintura española del siglo XIX

ledano hubo leído una bula falsa por la que se disolvía el parentesco entre los contrayentes.

De estos momentos anteriores a la boda entre Isabel y Fernando la iconografía es mucho menos abundante y tan solo podemos mencionar algunos cuadros como el titulado Doña Isabel la Católica humillando con su elocuencia a los que intentan robarla en el palacio de Madrigal, obra de Lino García (Madrid, último tercio del siglo XIX), que figuró en la Exposición Nacional de Bellas Artes de 1856, mientras que en la celebrada en 1864, el pintor sevillano Francisco Díaz Carreño expuso el lienzo Primera entrevista de los Príncipes $D^{a}$ Isabel de Castilla y D. Fernando de Aragón, en el que reflejó un fragmento de Prescott, de su Historia de los Reyes Católicos, reproducido en el catálogo: «A consecuencia de varios arreglos, el Príncipe, acompañado sólo de cuatro caballeros, salió de Dueñas en la tarde del dia 15 de octubre para la cercana ciudad de Valladolid, y en ésta fué recibido por el Arzobispo de Toledo, quien le condujo á la habitación de su futura... Gutierre de Cárdenas fué el que primero se le hizo ver á la Princesa, exclamando al mismo tiempo: Ese es, ese es en memoria de lo cual se le permitió poner en su escudo SS cuya pronunciación se asemeja tanto a su exclamación. Duró la entrevista más de dos horas y en ella se ajustaron los preliminares del matrimonio, el cual se verificó al dia siguiente» (Cat. 81, pp. 17-18).

Tras la boda de Isabel, Enrique IV volvió a reconocer a Juana la Beltraneja como heredera legítima, contando con el apoyo de algunos nobles, entre ellos el marqués de Villena y el arzobispo Carrillo que tras jugar un decisivo papel en la boda de Isabel y Fernando, había cambiado de bando.

El monarca castellano falleció en Madrid el día 11 de diciembre de 1474 y al día siguiente Isabel I era proclamada en Segovia reina de Castilla, aunque surgió entonces una enojosa cuestión que iba a desestabilizar el inicio del reinado, pues Fernando pretendió la corona castellana por ser el varón más cercano al fallecido Enrique IV, contando con el apoyo del almirante don Fadrique Enriquez. Finalmente se firmó la Concordia de Segovia (1475), por la que se igualaban los derechos de ambos y se acordaba la redacción de los documentos en común.

Cuando ya los monarcas castellanos estaban unidos, el rey Alfonso V de Portugal celebró en Plasencia sus esponsales con la Beltraneja y después penetró en Castilla por Zamora y Toro. Para allegar fondos, Isabel y Fernando celebraron Cortes en Medina del Campo en agosto de 1475 y mientras que Isabel se instaló en Tordesillas para atender el aprovisio- 
namiento del ejército, Fernando dirigió personalmente las operaciones militares y obtenía un gran triunfo en Toro, el 1 marzo 1476.

Este triunfo de Fernando el Católico en la Batalla de Toro se encuentra decorando uno de los plafones del techo de la Sala de Sesiones del Palacio de la Diputación de Zamora, pintura ejecutada entre 1880 y 1882, y representa «Cuando cesó la persecución y se enviaron a Zamora ocho banderas portuguesas, el pendón real y el botín, el rey don Fernando, que ya estaba reconocido en la ciudad, mandó que le llevasen la seña, y tomando la banda de tafetán verde puesta sobre el pecho, la puso con sus manos sobre las bermejas de Viriato». Fue pintada por Ramón Padró (Barcelona, 1848 - Madrid, 1915) teniendo como resultado una pintura de notable corrección y convencionalismo.

\section{La unión de las coronas de Castilla y Aragón}

El día 19 de enero de 1479 falleció el rey Juan II de Aragón y don Fernando heredó el trono aragonés, uniéndose así las coronas de Castilla y Aragón y emprendiendo ambos monarcas numerosas empresas, muchas de ellas, por su importancia, objeto de la atención de nuestros pintores de historia, destacando entre ellas la Conquista de Granada y el Descubrimiento de América que son objeto de estudio aparte.

Dedicaremos ahora nuestra atención a dos grandes bloques de pinturas. El primero de ellos lo definimos como Las tareas de gobierno y en él recogemos algunos lienzos que representan a los monarcas actuando en función de sus altas obligaciones, pudiendo citar como ejemplo el lienzo de Víctor Manzano y Mejorada (Madrid, 1831 - 1865), Los Reyes Católicos en el acto de administrar justicia, de grandes dimensiones, 350 x $400 \mathrm{~cm}$, firmado y fechado en 1860, que figuró en la Exposición Nacional de Bellas Artes celebrada en ese año en la que obtuvo segunda medalla, siendo adquirido por la reina Isabel II y enviado posteriormente a la Exposición Universal de Londres de 1862. En la actualidad se encuentra en el Palacio Real de Madrid. En un amplio salón, destacan al fondo, en el último plano, los reyes Isabel y Fernando, en sus tronos, bajo un dosel con un gran escudo con las armas de todos los reinos de las coronas de Castilla y Aragón. A sus lados, en dos bancos dispuestos lateralmente, los oidores del Consejo y en primer plano un escribano, junto al que están dos maceros y otros personajes, a ambos lados (Fig. 2). 


\section{Los Reyes Católicos en la pintura española del siglo XIX}

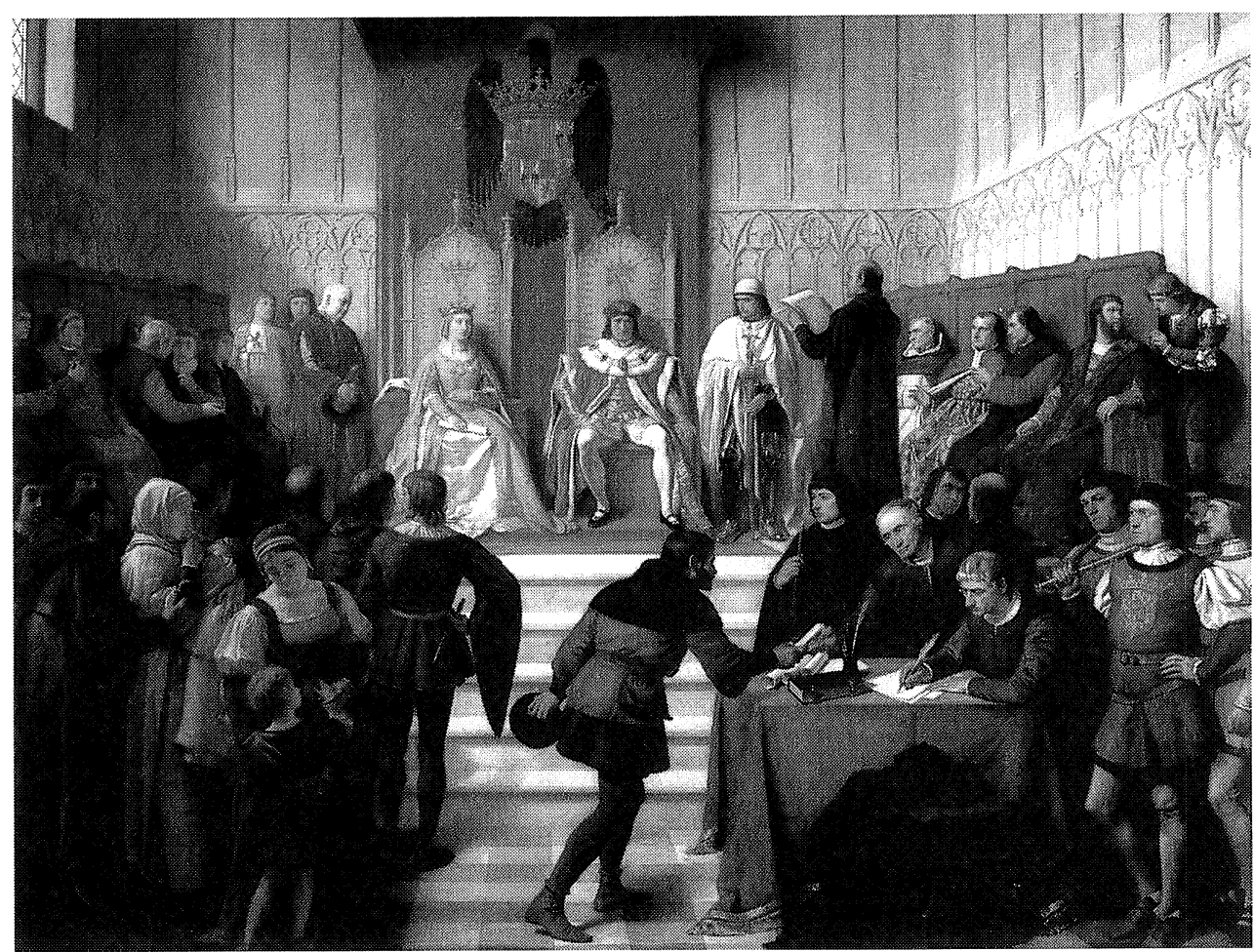

Fig. 2. Víctor Manzano y MeJorada, Los Reyes Católicos en el acto de administrar justicia, Madrid, Palacio Real.

También debemos recordar algunos otros cuadros, como el de José María Sobejano (Murcia, 1852 - 1918), que representa una Entrada de los Reyes Católicos en Murcia, óleo sobre lienzo de 30 x 50 cm, que se conserva en el Museo de Bellas Artes de Murcia.

Pero sin lugar a dudas, uno de los cuadros más singulares que muestran estas tareas de gobierno es el cuadro de Emilio Sala y Francés (Alcoy, Alicante, 1850 - Madrid, 1910) titulado Expulsión de los judíos de España (año de 1492), que figuró en la Exposición Nacional de Bellas Artes con el siguiente texto de Prescott: «Los Judíos, que habían tenido aviso de lo que pasaba, recurrieron á su poderosa politica ordinaria para granjearse la protección de los reyes; comisionaron á uno de los suyos para hacer un donativo de 30.000 ducados, con destino a los gastos de la guerra de los moros; pero esta negociación fue desconcertada de un modo violento por el inquisidor general Torquemada, el cual, entrando en el salón del palacio donde los reyes daban audiencia al comisionado judío, y sacando un crucifijo de debajo de los hábitos, le presentó, exclamando: $J u$ - 
das Iscariote vendió a su màestro por 30 dineros de plata; Vuestras Altezas le van a vender por 30.000; aquí está; tomadle y vendedle. $\mathrm{Y}$ dicho esto, aquel frenético sacerdote arrojó el crucifijo sobre la mesa, y salió. Los reyes, en vez de castigar semejante atrevimiento, o de despreciarle como simple arrebato de un loco, se quedaron aterrados» (cat. 885, pp. 177-178). De medidas 313 x 280 cm, se conserva en el Museo del Prado.

Este mismo tema tiene un pequeño cuadro del pintor Alejo Vera (Viñuelas, Guadalajara, 1834 - Madrid, 1923), de 1876, que se conserva en la Caja Provincial de Guadalajara y que se ha titulado Disputa ante los reyes. Representa una estancia en la que los Reyes Católicos ocupan un doble sitial y delante de ellos aparece el judío y el inquisidor Torquemada, que con un crucifijo en su mano derecha, que levanta ante los reyes, lo señala con la mano izquierda recordando el texto que antes transcribíamos $^{8}$.

Nos ocuparemos ahora de otras escenas con momentos de la intimidad familiar de los monarcas, particularmente de la reina Isabel y de sus afectos y sentimientos y entre ellas destacaremos el lienzo, en paradero desconocido, que la pintora Luisa Rodríguez de Toro mostró en la Exposición Nacional de Bellas Artes de 1856, titulado La reina Isabel la Católica dando lección con doña Isabel (sic) Galindo y curiosamente, otra mujer, la condesa de Velarde, mostraba en la Exposición Nacional de Bellas Artes de 1884 otro lienzo, de 61 x $45 \mathrm{~cm}$, con la misma temática, La Reina Doña Isabel la Católica con Doña Beatriz Galindo (la Latina) (cat. 716, p. 140). En ambos casos, estas dos pintoras quisieron poner de manifiesto la formación de la reina doña Isabel que recibió clases de latín de Beatriz Galindo (Salamanca, 1475? - Madrid, 1534), quien tuvo gran influencia en la corte y estuvo casada con el general Francisco Ramírez de Madrid, secretario del rey Fernando.

$\mathrm{Y}$ en relación con esta pintura queremos poner otros dos lienzos en los que se plasma la educación, no solo intelectual sino también humana, recibida por los hijos de los Reyes Católicos. El primero de ellos, Isabel la Católica presidiendo la educación de sus hijos, $(254 \times 335 \mathrm{~cm})$ depositado en la Audiencia Territorial de Barcelona desde 1886, fue pintado por Isidoro Lozano (Logroño, 1826 - ?) y presentado a la Exposición Nacional de Bellas Artes de 1864. Se inspira en el siguiente texto de Prescott, de su Historia de los Reyes Católicos: «La Reina manifestó la mas viva solicitud por la educación de sus hijos; sus hijas estaban dotadas de escelentes disposiciones naturales, que secundaron los esfuerzos de su madre, y para su enseñanza se emplearon los maestros más competentes, asi na- 


\section{Los Reyes Católicos en la pintura española del siglo XIX}

turales como extranjeros, y especialmente de Italia. Su instrucción se confió mas particularmente á dos hermanos naturales de aquel país llamados Antonio y Alejandro Geraldino. El Principe D. Juan se distraía de sus estudios serios y filosóficos dedicándose á otros mas agradables, y dedicó muchas de sus horas de recreo a la música, para lo cual tenía un gusto muy delicado, habiendo hecho en ella notables adelantos, hasta el punto de tocar muy bien diferentes instrumentos» (cat. 217, p. 42).

En el lienzo de Lozano aparece la reina Isabel, sentada y junto a ella la infanta doña Catalina, que le está enseñando un escrito aunque la soberana mira a su hijo, el príncipe don Juan que toca un órgano mientras que sus hermanas, Juana y María, junto a la ventana, cantan, mientras que Isabel borda y junto a ella, la marquesa de Moya. En el fondo, los hermanos Geraldino.

La segunda de las pinturas (de 328 x $487 \mathrm{~cm}$ ) fue ejecutada por Salvador Martínez Cubells (Valencia, 1845 - Madrid, 1914), se titula La educación del Príncipe don Juan y se conserva en el Palacio del Senado en Madrid en depósito del Museo del Prado desde 1881. Figuró en la Exposición Nacional de Bellas Artes de 1878, en la que alcanzó la primera medalla y su contenido puede ser comprendido por el texto de González de Oviedo, de su obra Libro de la Cámara del Príncipe D. Juan e oficios de su casa e servicio ordinario, que aparece en el Catálogo y que transcribimos: «...fuéle dicho á la Reyna Catholica que el Príncipe, su hijo, sería escaso, porque algunos indicios dauan lugar de tal sospecha; e como prudente e magnánima, pensó que forma podría tenerse para librar á su hijo de tal defecto e ensenarle á ser liberal; e vsó de una linda arte en que le acostumbró á dar e hazer mercedes, porque de poco en poco hiciese hábito esa virtud en el Príncipe. Para esto, la Reyna llamó á Johan de Calatayud, camarero del Príncipe, e le mandó hazer inuentario por duplicado todas las rropas e vestidos del Príncipe para el postrero dia del mes de Junio (que en tal dia nasció el Príncipe). Venido pues aquel dia e lleuados todos los vestidos delante de la Reyna e inuentariados, mandó llamar al Príncipe e venido ante su madre, thenia la Reyba vn memorial en la mano e dixole: Hjo, mi angel, los príncipes no han de ser rropauejeros ni tener las arcas de su cámara llenas de los vestidos de sus personas; de aqui adelante tal dia como oy cada año, quiero que delante de mi rrepartais todo eso por vuestros criados e los que os sirven e aquellos aquien quisieredes hacer merced. Tomad esta memoria e el vuestro escribano de cámara que ay está, Diego Cano, tiene otra tal, e como fueredes lehiendo, asi en la margen de la otra tal Memoria vaya el escriuano escriuiendo á quien mandais e quereis que se le dé la rropa e sayo e lo que mandareis darle, 


\section{Wifredo Rincón García}

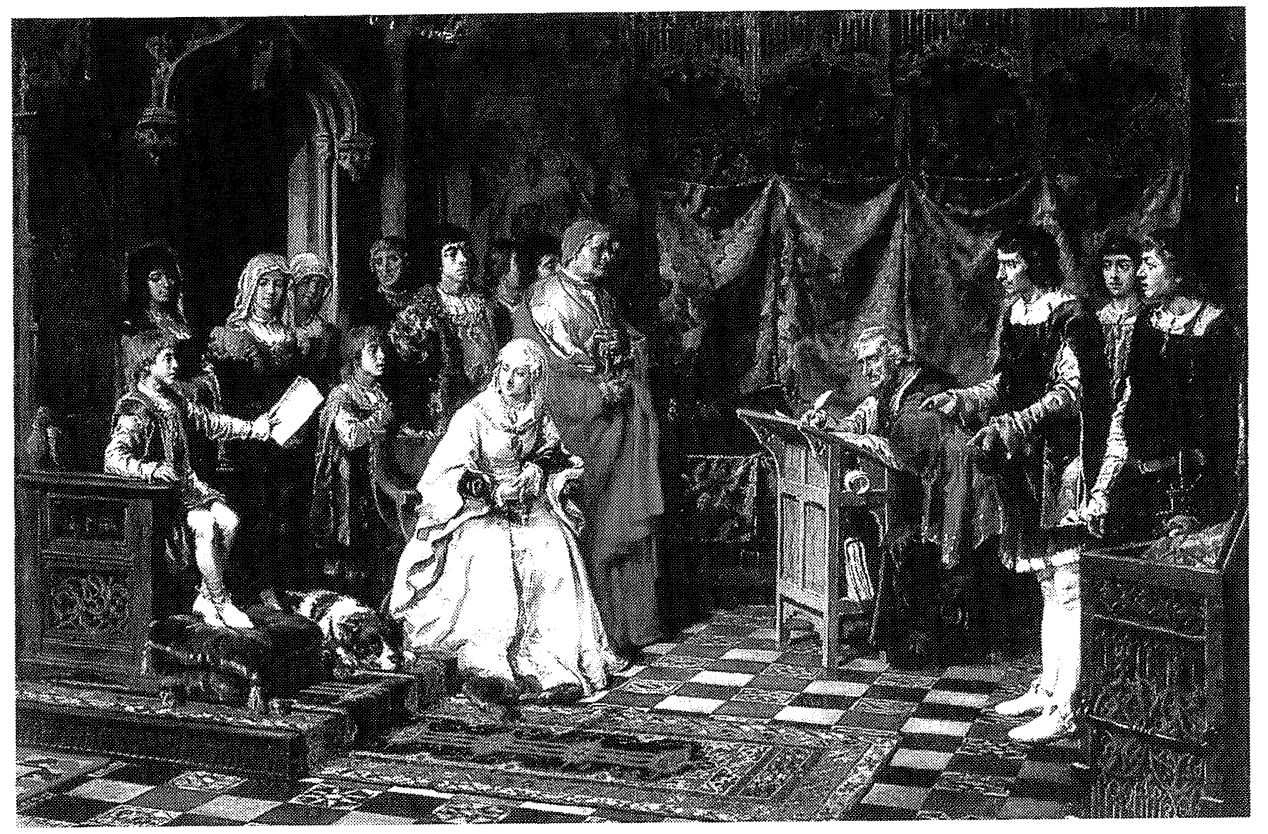

Fig. 3. Salvador Martínez Cubells, La eduación del Príncipe don Juan, Madrid, Palacio del Senado

para que vuestro camarero se lo envie despues de vuestra parte. E en lo que entre el año quisieredes hacer merced á algún cauallero ó persona señalada, mandádselo, e cuando se lo dieredes no se lo digais primero al que se lo dais ni nunca se lo cahirais ni hableis en ello, ni se os acuerde cosa que dieredes ni olvideis lo que os dieron, conque otros os siruan: porque sois obligado de buena consciencia e como Príncipe agradecido a lo satisfacer e gratificar. Ohido esto, el Príncipe besó la mano á la Reyna, e tomando el memorialse asentó e dixo: Tal sayo e tal capa e tal jubon dense á D. Jaime de Portugal, etc., etc., etc.». (Cat. 225, pp. 47-48). Martínez Cubells interpreta el texto antecedente con gran fidelidad, rodeando a la reina y al príncipe una serie de personajes de la corte (Fig. 3).

También queremos recoger otros lienzos, y entre ellos ocupa un destacado lugar el que representa Doña Isabel la Católica en la Cartuja de Miraflores, obra de Luis Álvarez Catalá (Madrid, 1836 - 1901) que figuró en la Exposición Nacional de Bellas Artes de 1866, en la que obtuvo consideración de medalla de segunda clase. De $175 \times 186 \mathrm{~cm}$, se encuentra depositado desde 1928 en la Universidad de Granada. El pintor utiliza un texto histórico, que figura en el catálogo, aunque no precisa su autor: «Habiendo doña Isabel la Católica manifestado varias veces el deseo de 


\section{Los Reyes Católicos en la pintura española del siglo XIX}

visitar la Cartuja de Miraflores, situada en las inmediaciones de Búrgos, con objeto de contemplar los restos de su padre D. Juan II, que se hallaban depositados en la Sacristía, interin se terminaba su sepulcro, anunció a los religiosos su propósito y con motivo de su entrada solemne en aquella Capital en el año de 1486, se dirigió al Monasterio acompañada de la infanta Isabel y de algunos personajes de la Corte. La comunidad, correspondiendo á los deseos de la Reina, sacó el féretro al limite de la clausura abriéndole en su presencia» (cat. 13, pp. 8-9). Así, en la puerta de la iglesia, aparece la reina Isabel ante el féretro abierto de su padre. Fuera del templo a la izquierda fueron representados algunos cartujos, uno de ellos con cruz alzada, mientras que a la derecha aparecen la infanta Isabel y varios personajes de la corte.

\section{La culminación de la Reconquista}

La guerra de Granada, con la que se culminaría el largo proceso de la Reconquista, es el gran objetivo que los Reyes Católicos se propusieron en su reinado para alcanzar la unidad española y tuvo su inicio tras la noche del 26 de diciembre de 1481 cuando el sultán de Granada Abú-lHassan atacó por sorpresa la villa de Zahara, para ganar prestigio entre los suyos. La respuesta cristiana se produjo poco después y también por sorpresa, cuando una noche el marqués de Cádiz tomó la villa de Alhama, situada estratégicamente en el camino desde Granada a Málaga, por lo que fue intentada recuperar en tres ocasiones.

La presencia de los Reyes Católicos en la guerra de Granada -Fernando acudió casi desde el primer momento al frente de la misma, mientras que Isabel se encargaba de reunir dinero y tropas aunque a partir de 1486 se unió a los ejércitos y estuvo presente en el cerco de Málaga, en las operaciones que condujeron a la rendición de Zagal y, sobre todo, en el cerco de Granada- se pone de manifiesto en un importante número de pinturas del siglo XIX que describen momentos distintos de la contienda y para cuya ejecución, como es habitual en la pintura de historia, los artistas se inspiran en textos de cronistas e historiadores.

Siguiendo el desarrollo de la guerra, corresponde al momento más antiguo la pintura titulada Batalla de Lucena, que presentó Francisco de Paula Van Halen (Vich, Barcelona, principios del siglo XIX - Madrid, 1887) a la Exposición Nacional de Bellas Artes de 1856, apareciendo en el catálogo con el siguiente texto: «Se dio esta batalla en las inmediaciones de Lucena el 21 de abril de 1843. Sitiada la ciudad con poderoso ejér- 
cito el rey moro Boabdil; defendía la plaza don Diego Fernández de Córdoba, Alcaide de los Donceles, con sus auxiliares el Conde de Cabra, su tío, don Alfonso de Córdoba, Señor de Zuheros, López de Mendoza, Diego de Cabrera, el Alcaide de Baena, y otros esforzados caballeros. Favorecidos por una densa niebla, hicieron una salida, de cuyas resultas se pronunciaron en completa derrota las huestes de Boabdil. Abandonado éste de sus tropas, defendiéronle solamente unos cuantos caballeros moros, que, rodeando su persona sucumbían uno tras otro a los pies de su caballo. Fue aprisionado Boabdil, y los infieles, casi todos pasados a cuchillo. El momento representado por el autor es cuando Boabdil anima a los pocos fieles a su guardia, rodeado por sus huestes cristianas».

Un momento posterior, en esta misma batalla, fue representado por Pedro González Bolívar en su cuadro Prisión de Boabdil último rey de Granada, en la batalla de Lucena, de 270 x $371 \mathrm{~cm}$, en paradero desconocido, que presentó a la Exposición Nacional de Bellas Artes de 1878 y para la que se inspiró, tal como aparece en el catálogo, pero sin transcribir el texto, en la Historia de España, de Lafuente, tomo IX, capítulo IV.

La toma de la ciudad de Loja por Fernando el Católico en mayo de 1486 sirvió como pretexto histórico a Eusebio Valldeperas (Barcelona, 1827 - Madrid, 1900) para su cuadro titulado la Toma de Loja por D. Fernando el Católico, que figuró en la Exposición Nacional de Bellas Artes de 1862 (196 x $130 \mathrm{~cm})$. El asunto, fue extraído de la Historia de España, de Lafuente, cuyo texto se recoge en el catálogo: «El Rey Chico, Boabdil, salió casi desfallecido en compañía de Gonzalo de Córdoba á besar la mano á D. Fernando que le recibió con la dulzura y la benignidad que acostumbraba á usar con los vencidos» (cat. 268, p. 48). Adquirido por la reina Isabel II, se encuentra en la actualidad en los Reales Alcázares de Sevilla.

Este mismo pintor había presentado en la Exposición Nacional de Bellas Artes de 1860 otro cuadro de la guerra de Granada, en este caso titulado $D^{a}$ Isabel la Católica, de paso para Moclin, visita en Loja á los heridos y enfermos, á quienes socorrió con dineros á proporción de su clase. El cuadro, $(258 \times 300 \mathrm{~cm})$, fue igualmente adquirido por la reina Isabel II y figura en la colección del Palacio Real de Madrid.

La escena reproduce el texto que aparece en el catálogo, aunque sin autor: «Estando el Rey D. Fernando en Moclin, mandó llamar á la Reina $\mathrm{D}^{\mathrm{a}}$ Isabel, para que con su presencia animára el espíritu de las tropas. La Reina se puso en camino, acompañada de la Infanta $\mathrm{D}^{\mathrm{a}}$ Isabel, de su confesor, el Obispo de Ávila, Fr. Hernando de Talavera, damas, pajes y ca- 


\section{Los Reyes Católicos en la pintura española del siglo XIX}

balleros, pasando por la ciudad de Loja, recien tomada á los moros» (cat. 252 , p. 35). De acuerdo con este texto, aparece en el centro, de perfil, la reina Católica a la que acompaña su hija Isabel, cuando se acerca a un enfermo que yace en una cama y junto a la reina aparecen varios caballeros, damas y fray Hernando de Talavera.

Un nuevo paso en la guerra significó la conquista de la ciudad de Málaga en 1487 cuyo cerco se había prolongado a lo largo de tres meses. Esta página histórica es la interpretada por Eduardo Cano de la Peña (Madrid, 1823 - Sevilla, 1897) en el cuadro Los Reyes Católicos recibiendo á los cautivos cristianos en la conquista de Málaga que figuró en la Exposición Nacional de Bellas Artes de 1866, en cuyo catálogo se contiene también el siguiente texto de Bernáldez: «E luego demandó los cautivos cristianos que en Málaga estaban, é fizo poner una tienda cerca de la puerta de Granada donde El é la Reina é la Infanta su hija les recibieron, y fueron entre hombres y mujeres los que allí los moros les trajeron fasta doscientas personas, é á la puerta por do salieron estaban muchas personas con cruces é pendones del Real que fueron en procesión con ellos fasta donde estaba el Rey é la Reina atendiéndolos. E llegando donde SS. AA. estaban todos se humillaron é caian por el suelo, é le querian besar los pies, é ellos no lo consintieron mas dabanles las manos, é cuantos lo veian dabanle loores á Dios é lloraban con ellos con alegria, los cuales salian tan flacos é amarillos con la gran hambre; que querian parecer todos con los fierros é adabones á los pies é los cuellos, é barbas muy cumplidas. E de que besan los pies al Rey é la Reina, loaron todos á Dios muchos rogándole por la vida y acrecentamiento de SS. AA. E luego el Rey les mandó dar de comer é de beber é les mandó desherrar, é les mandaron vestir é dar limosna para dispensa de cada uno donde quisiere ir é asi fué fecho é cumplido. E entre estos cautivos habia personas que asi diez é quince é veinte años que estaban cautivos, é otro menos». (Cat. 68, pp. 16-17).

Cano de la Peña en este cuadro (300 x $480 \mathrm{~cm}$ ), en el Museo de Sevilla, interpreta el texto de Bernáldez con brillantez, destacando la figura de la reina Isabel, que aparece centrando la composición, muy bien iluminada, casi en actitud beatífica, acogiendo, junto al rey Fernando y otros miembros de la corte, a los cautivos cristianos liberados tras la conquista de Málaga.

El último capítulo de la guerra de Granada fue la conquista de la capital del reino nazarita y la entrada de los Reyes Católicos en Granada, tema este que ha tenido una brillante representación plástica desde poco 
después de su consecución, si pensamos, por ejemplo, en la sillería baja del coro catedralicio de Toledo. Por lo que se refiere a la pintura, debemos destacar la magnífica pintura al fresco ejecutada por Francisco Bayeu en 1763 en la bóveda de la antigua pieza de comer y besamanos del cuarto de la reina, actualmente parte del comedor de gala del Palacio Real de Madrid, de la que se conservan distintos bocetos.

Por lo que corresponde al siglo XIX, queremos recordar en primer lugar un lienzo en el que José Galofre pintó Las capitulaciones de Santa Fe (298 x $480 \mathrm{~cm}$ ), en el que representó a Isabel la Católica firmando las capitulaciones. El cuadro, realizado en 1854 para Isabel II, se conserva en el Palacio Real de Madrid, y se exhibió en la Exposición Universal de París de 1855, en cuyo Catálogo aparece así descrito: «Los Reyes Católicos imponen al embajador árabe El Kasim las segundas capitulaciones de Granada. Durante la firma de este tratado, Cristóbal Colón, a punto de comenzar su primer viaje, conversa con sus protectores. Se observa, cerca de Cristóbal Colón, a su protectora más devota, la mejor amiga de Isabel la Católica, doña Juana de Bobadilla, marquesa de Moya».

De otras muchas pinturas sobre esta temática queremos recordar que en 1846 Francisco de Paula Van Halen presentó al infante don Francisco de Asís un boceto de la Rendición de Granada, cuya ejecución concluyó al parecer en 1850, obra con numerosos personajes, en dos grupos muy compactos, en la que puede advertirse una notable influencia de Las lanzas de Velázquez, pero sobre todo prestaremos nuestra atención al lienzo titulado La rendición de Granada, de Francisco Pradilla Ortiz (Villanueva de Gállego, Zaragoza, 1848 - Madrid, 1921), pintado por encargo del Presidente del Senado, el Marqués de Barzanallana y ejecutado en Roma entre los años 1879 y 1882, tal como figura en el anverso del lienzo: «F. Pradilla. Granada-Roma, 1882».

Indudablemente, esta obra de Pradilla puede considerarse como una de las más representativas de las pinturas de historia españolas del siglo XIX, siendo claro ejemplo de la facilidad y grandes dotes de este artista para las grandes composiciones, que desarrolló en un lienzo de 330 x $550 \mathrm{~cm}$, situándole muy por encima de otros pintores del momento.

El contenido del cuadro se pone de manifiesto por la carta que le envía Pradilla al marqués de Barzanallana y que transcribimos: «Excmo. Sr. Marqués de Barzanallana. Muy señor mío, de todo mi respeto y consideración: Mi cuadro La entrega de Granada destinado por Vd. al salón de conferencias debe llegar á Madrid, si no ha llegado ya, de un momento á otro. Como á Vd. debo, en primer lugar, el haberlo ejecutado, aprovecho 


\section{Los Reyes Católicos en la pintura española del siglo XIX}

esta ocasión para dar á Vd. las gracias. Continué mi trabajo según indicación que, por encargo de Vd. me hizo el señor Mazo. Varios contratiempos de salud me han impedido terminarlo antes. No tengo más pretensión sobre mi obra que la de haberme esforzado por cumplir bien mi compromiso. Usted comprenderá, señor Marqués, á la vista del cuadro que el desarrollo de mi composición en sentido realista pero que no excluye la poesía y grandeza con que se nos presenta envuelta la Historia, exigían más atención, tiempo y dispendios que si fuese tratada con carácter decorativo, donde se fía más á la memoria, dando ocasión á mi solicitud de aumento. Usted verá, Sr. Marqués, pues es cosa perceptible para los prácticos en cosas de arte, que mi composición es un segmento de semicírculo que el ejército cristiano forma desplegado, paralelo a la carretera. En la planta supongo que en medio del semicírculo están situados los caballeros, teniendo o guardando en medio a las damas de la Reina; ésta, el Rey y sus dos hijos mayores están situados delante y en el centro del radio con los pajes y reyes de armas á los lados. El Rey Chico avanza por la carretera á caballo hasta la presencia de los Reyes, haciendo ademán de apearse y pronunciando la sabida frase. El Rey Fernando le contiene. Con Boabdil vienen á pie, según las capitulaciones, los caballeros de su casa. Supongo el diámetro del semicírculo algo oblicuo á la base del cuadro, y esta disposición permite que, sin amaneramiento ni esfuerzo alguno, se presenten los tres Reyes al espectador como más visibles. A ello contribuyen también las respectivas notas de color: blanco-azul-verdastro, la Reina y su caballo; rojo, el rey Fernando, negro, el Rey Chico. Habiendo cortado mi composición cerca de los Reyes, se presentan en el cuadro, por orden perspectivo: primero, un rey de armas, tamaño natural, figura voluminosa, que á algunos parecerá excesiva á causa del sayal y dalmática que la cubren y de la vecindad del paje de la reina por comparación. Sigue este paje que sujeta el caballo árabe (por ser de menor volúmen) de la Reina, el cual es blanco, está piafando y no da lugar al movimiento erguido de Isabel, que viste saya y brial de brocado verde-gris forrados de armiño, manto real y brocado azul y oro con orlas de escudos y perlas, ciñendo la tradicional toca y la corona de plata dorada que se conserva en Granada. Sigue su hija mayor Isabel, viuda reciente del Rey de Portugal; viste de negro y monta una mula baya. Después el Príncipe D. Juan sobre caballo blanco y coronado de diadema. Como los hijos están entre los Reyes, sigue Don Fernando (siempre con la disminución perspectiva), cubierta su persona con manto veneciano (que usaba según diversos datos que poseo) de terciopelo púrpura contratallado, montando un potro andaluz cubierto de paramentos de brocado. Su paje, que lleno de admiración contempla al Rey Chico, tiene al caballo por las bridas fal- 
sas. Corresponde después el otro rey de armas y detrás está, entre Torquemada y varios prelados, el confesor de la Reina. Volviendo al primer rey de armas, los caballeros que hay á la margen del cuadro son: el Conde de Tendilla, cubierto de hierro, montando un gran potro español; el gran maestre de Santiago, sobre un potro negro; Gonzalo de Cordova, que conversa con una de las damas; el de Medina-Sidonia, y otros caballeros de los que no conozco retratos. Detrás de D. Fernando el Marqués de Cádiz y los pendones de Castilla y de los Reyes. He puesto cipreses detrás de la Reina para destacarla por claro en su masa sombría y caracterizan también el pais; Boabdil, al trote de su caballo negro, árabe de pura sangre, ligeramente paramentado, avanza y sale de la carretera, inclinandose para saludar al Rey y entregarle las dos llaves, que á prevención traía. El paje negro que guía su caballo camina inclinado, confundido entre la grandeza de los Reyes cristianos, y en los caballeros moros que, según el ceremonial, vienen á pie detrás del Rey Chico, he querido manifestar los diversos sentimientos de que se encontrarían poseídos en semejante trance, más ó menos contenidos en la ceremonia, según el propio carácter. Trompeteros y timbaleros en el ala del ejército cristiano que á lo lejos se divisa entre Boadbil y el Rey cristiano, comitiva de moros, un alero de la mezquita, los chopos que indican el curso del Geníl, que no se ve por correr profundo y en el fondo. La Antequeruela con sus muros, parte de Granada, las torres bermejas de la Vela, que, con parte de los adarves es lo único que se divisa de la Alhambra desde este punto. Esto es lo que se ve en mi cuadro, y la gente dice que ve más, porque creo haberlo compuesto con la mayor sobriedad posible, dada la complicación del asunto. En Roma gustó más de lo que puedo pretender; yo no estoy contento sino de la tonalidad del aire libre como conjunto, de haber conseguido detalle dentro de éste, y de la disposición en general como perspectiva exacta y como ceremonial. En lo demás me han faltado medios ó condiciones. Quizás sea ya inútil esta mal pergeñada explicación si llega el cuadro antes que la carta; pero al menos descubrirá Vd. los propósitos que me guiaron al tratar así mi composición. Deseando perfecta salud á Vd. y su familia, se ofrece suyo afectísimo seguro servidor Q.S.M.B., Francisco Pradilla. Roma, 13 de junio de $1882 »^{9}$ (Fig. 4).

También debemos mencionar otro gran cuadro de historia, titulado ¡Granada, Granada, por los reyes don Fernando y doña Isabel que fue pintado por Carlos Luis de Ribera por encargo de la reina Isabel II, ejecutando un boceto en 1853, aunque la obra definitiva, de $302 \times 582 \mathrm{~cm}$, que se encuentra en la catedral de Burgos, lleva la fecha de 1890. Representó Ribera el momento en que a la vista de la ciudad de Granada, 


\section{Los Reyes Católicos en la pintura española del siglo XIX}

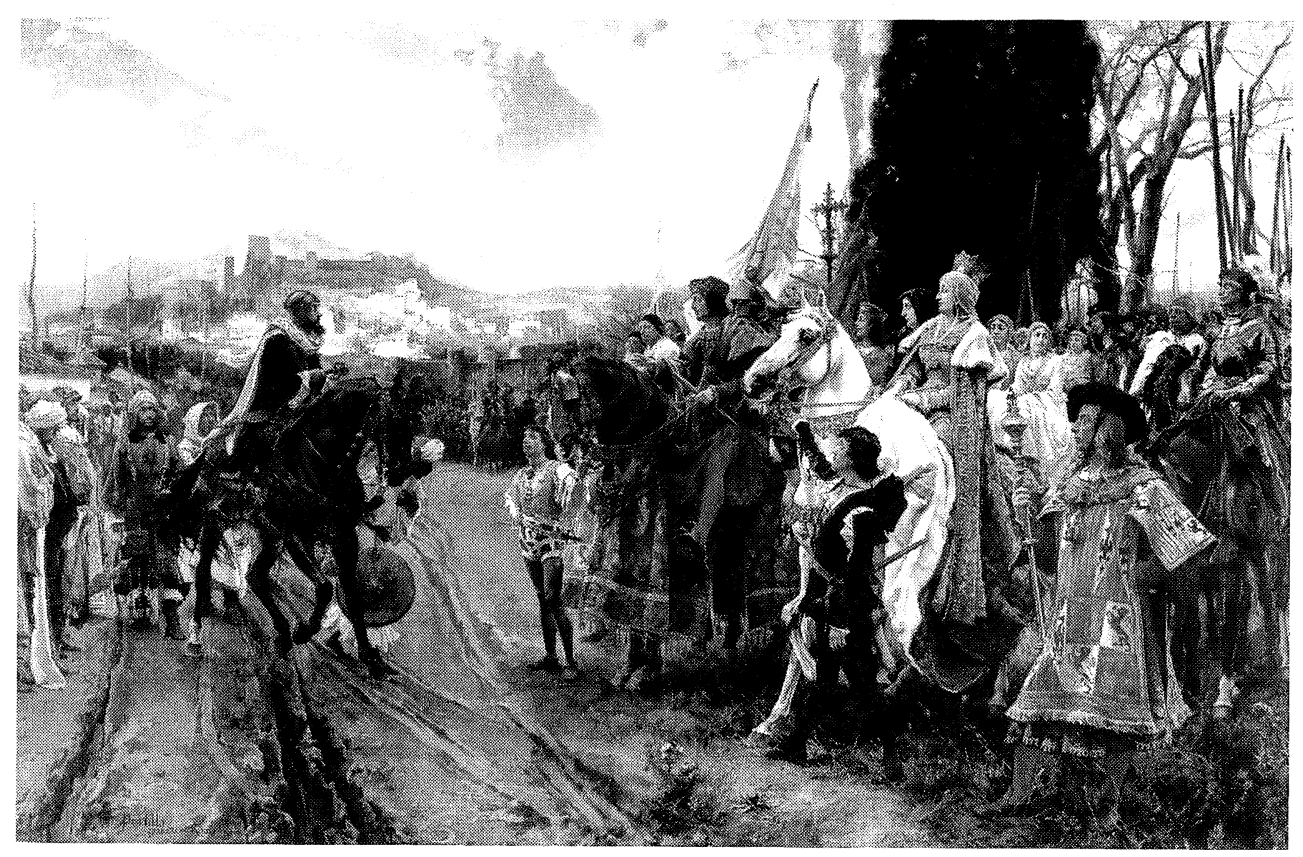

Fig. 4. Francisco Pradilla, La rendición de Granada, Madrid, Palacio del Senado

fue cantado un Te Deum en acción de gracias. En el centro aparecen la reina Isabel, con las manos extendidas, y el rey don Fernando, postrados ambos de rodillas y rodeados de otras muchas figuras, entre ellas el príncipe don Juan, los marqueses de Cádiz y de Villena, los condes de Tendilla y Ureña, el marqués de Aguila, el duque del Infantado, el conde de Cabra, Gonzalo Fernández de Córdoba, Hernán Pérez del Pulgar, el conde de Cifuentes y los cadíes Hiaga y Mohamed que se habían convertido al cristianismo, además de otros cortesanos y pajes. También eclesiásticos como el cardenal Mendoza, el padre Marchena y fray Hernando de Talavera, además de otros caballeros y Cristóbal Colón.

\section{Los Reyes Católicos y la empresa americana}

Uno de los capítulos más destacados del reinado de los Reyes Católicos fue, sin lugar a dudas, la culminación del sueño de Cristóbal Colón y la llegada del Almirante de Castilla hasta las Antillas menores, que se ha dado en denominar por la historiografía de maneras muy distintas, pues si bien es conocida tradicionalmente como el Descubrimiento de 
América, los últimos años nos han regalado nuevas definiciones para la gesta colombina como $E l$ encuentro entre dos mundos, o la que nosotros proponemos en este trabajo, la Empresa americana.

Numerosos son los cuadros del siglo XIX ${ }^{10}$, sobre todo de su segunda mitad, cuando se aproximaba la celebración del IV Centenario del Descubrimiento de América, que tienen como protagonistas a los Reyes Católicos y a Cristóbal Colón y su proyecto, y que podemos concretar en cinco momentos distintos y consecutivos.

El primero de ellos, tras la estancia del navegante en el convento franciscano de Santa María de la Rábida, donde encontró cobijo y apoyo para su empresa, es el encuentro de Cristóbal Colón con los Reyes Católicos que se produjo en Córdoba en 1486 y que describe así Lafuente: «Apareció el extranjero con modesta gravedad a la presencia de los soberanos de Castilla... Fernando, frío y cauteloso, pero nunca indiferente a las grandes ideas; Isabel, más expansiva y más entusiasta de los grandes pensamientos, ambos oyeron a Colón benévolamente».

Los diferentes artistas que han plasmado esta entrevista de Colón con los Reyes Católicos, siguiendo las páginas escritas por los más importantes historiadores del momento, han planteado también un claro proceso secuencial, pues mientras unos han plasmado la llegada y presentación de Colón ante los monarcas, y en otras ocasiones es solamente la Reina Isabel quien recibe a Colón, esta presentación es seguida de la «explicación» por parte del navegante de su proyecto.

En la Exposición Nacional de Bellas Artes de 1864, con el número 155 figuró un lienzo de Luis Jiménez Aranda (Sevilla, 1845 - Pontoise, Francia, 1928), titulado Cristóbal Colón al venir a proponer a los Reyes Católicos el descubrimiento del Nuevo Mundo, que también se ha titulado Colón proponiendo a los Reyes Católicos el descubrimiento del Nuevo Mundo y por el que su autor obtuvo una mención de honor. Hoy en paradero desconocido, no podemos describir su contenido, lo que sí puede hacerse con un boceto atribuido a Eduardo Rosales (Madrid, 1836 1873), titulado Colón ante los Reyes Católicos (óleo sobre lienzo, 0,80 x 1 $\mathrm{m}$ ) en colección particular madrileña, que figuró fuera de catálogo en la exposición Cuatro generaciones de pintores madrileños: Rosales y sus descendientes, celebrada en febrero-marzo de 1984 en la Sala Pablo Ruiz Picasso de la Biblioteca Nacional de Madrid. En un interior, con ventanales góticos, aparece la reina Isabel sentada en un trono y junto a ella, de pie, el rey Fernando. Detrás de ellos una dama, tal vez la infanta doña 


\section{Los Reyes Católicos en la pintura española del siglo XIX}

Juana y frente a los monarcas, Cristóbal Colón, que es presentado por un personaje, tal vez un eclesiástico.

Aunque sabemos que Rosales se interesó por este momento de nuestra historia, pues así se desprende de un dibujo, tinta sepia sobre papel, de 22,6 x 19,3 cm, firmado y fechado: «E. Rosales 66», y titulado al dorso Colón ante los Reyes Católicos, que se conserva en el Museo del Prado y ha figurado en distintas muestras sobre el infortunado pintor madrileño ${ }^{11}$, no podemos precisar que el boceto que nos ocupa sea obra de Rosales, pues guarda estrecha relación compositiva con otro lienzo, firmado por Manuel Crespo Villanueva (Ojacastro, Logroño), discípulo de Francisco Jover y activo en la segunda mitad del siglo XIX, titulado Presentación de Colón a los Reyes de España, óleo sobre lienzo, de 63 x $88 \mathrm{~cm}$, fechado en 1889, en paradero desconocido, que figuró en la Exposición Nacional de Bellas Artes de 1890 (cat. 217, p. 50). Reyero, que advierte la similitud de esta obra con el boceto de Rosales, apunta que «o se trata de una copia directa, o el supuesto boceto de Rosales es de Crespo. Dada la capacidad del pintor riojano para hacer versiones de Rosales no puede absolutamente descartarse la primera posibilidad, que, más verosimil, seguimos» ${ }^{12}$.

Eduardo Llorens Masdeu (Barcelona, ? - 1912) en su lienzo Colón ante la Reina Isabel la Católica, que forma parte de la serie de pinturas representando episodios colombinos ejecutados en 1880 para decorar el palacio del señor Samá en Barcelona, limita curiosamente la representación regia a la reina castellana que en un interior palaciego, sedente, bajo dosel, recibe a Colón, que aparece genuflexo ante la soberana, en el momento en el que es presentado por un caballero que se sitúa a su izquierda y que se dirige a la Reina. Otros personajes complementan la escena.

Por último mencionaremos otros cuadros, de la misma temática, pintados por Alejo Vera y Estaca (Viñuelas, Guadalajara, 1834 - Madrid, 1923), fechado en 1876; Salvador Sánchez Barbudo (Jerez de la Frontera, Cádiz, 1857-1917) y Ricardo Villegas Cordero (Sevilla, 1849-1896).

La exposición del proyecto colombino se pone claramente de manifiesto en un lienzo del pintor Lino García, que se ha titulado Colón ante los Reyes Católicos, aunque debería definirse con mayor concreción de la escena, pues representa el momento en el que Cristóbal Colón indica a los Reyes Católicos la ruta que propone para llegar a las Indias sobre una carta de marear que se encuentra extendida sobre un mesa y sobre la que 
también tiene su mano la reina que consulta con el cardenal Mendoza, que aparece a su lado. El rey Fernando, de pie, junto a su esposa, atiende también las explicaciones, afirmando Reyero, a propósito de este cuadro que, «a pesar de la torpeza técnica con la que se desenvuelven las figuras, reúne todas las condiciones de fácil lectura requeridas» ${ }^{13}$. Firmado y fechado, «Lino García fecit 1852» (ang. inf. dcho.), se trata de un óleo sobre lienzo, de 1,40 x 2,80 m, que se encuentra en Madrid, en el Cuartel General del Ejército del Aire. Este mismo momento representa otro lienzo, Colón ante los Reyes Católicos, de 0,41 x 0,52 m. en colección particular, firmado y fechado por Francisco Pradilla Ortiz en Roma en 1874. De este cuadro, del que ya nos hemos ocupado en distintas ocasiones ${ }^{14}$, destacamos que la entrevista se celebra en un lóbrego interior palaciego, donde solamente una ventana con vidriera gótica proporciona un rayo de luz que ilumina la estancia. La composición se articula en dos grupos de personajes que una la figura de Colón, de pie, que dirige su alocución a la reina Isabel que aparece sentada delante de la mesa donde aparecen desenrolladas las cartas marítimas con el proyecto de Colón, a las que también prestan atención el rey Fernando y el cardenal Mendoza. Junto a la reina, la figura de la infanta doña Juana y tras ella, dos personajes de la corte. Detrás de la figura de Colón, dos religiosos dominicos conversan. Como curiosidad, queremos poner de manifiesto como los rasgos fisionómicos de los Reyes Católicos y de doña Juana se corresponden con los que más tarde utilizará Pradilla en su cuadro de la Rendición de Granada.

Francisco Jover Casanova (Muro de Alcoy, Alicante, 1836 - Madrid, 1890) desarrollará este mismo momento en otro lienzo, en paradero desconocido, en el que en un interior gótico, aparecen los Reyes Católicos y Colón sentados en torno a una mesa que centra la reina Isabel, en el momento en el que el navegante expone sus planes que son seguidos con atención por el rey Fernando. Distintos personajes completan la escena.

También Pedro Mendigacha (Aranjuez, segunda mitad del siglo XIX) realizó otro cuadro titulado Colón exponiendo sus proyectos á los Reyes Católicos, de grandes dimensiones, $305 \times 500 \mathrm{~cm}$, en paradero desconocido, que figuró en la Exposición Internacional de Bellas Artes celebrada en Madrid en 1892 (cat. 765, p. 120).

Otros pintores limitan a la figura de la reina Isabel el protagonismo regio de la escena de la explicación del proyecto colombino, como sucede en el cuadro de José María Rodríguez de los Ríos y de Losada (Sevilla, 1826 - Puerto de Santa María, Cádiz, 1896), titulado Entrevista de Colón con Isabel la Católica en Córdoba, óleo sobre lienzo, de 250 x 500 cm, pin- 
tado en 1867, que forma parte de un friso con diez grandes lienzos de la historia de Córdoba para decorar el nuevo edificio del Círculo de la Amistad en esta ciudad andaluza. A la izquierda de la composición aparece la reina Isabel con Hernando de Talavera y varios personajes cortesanos, atendiendo las explicaciones que sobre un globo terráqueo hace Colón.

Un segundo momento en los prolegómenos de la gesta colombina lo va a protagonizar la reina Isabel cuando «vende o cede» sus joyas para sufragar la empresa americana, iniciativa ésta que va a tener una importante repercusión en la pintura decimonónica. El cuadro más antiguo que conocemos de esta temática, en la actualidad en paradero desconocido -fue propiedad de la reina Isabel II-, lo pintó hacia 1855 Francisco de Paula Mendoza y Moreno (Madrid, 1812 - 1885) autor de un interesante Manual del Pintor de Historia y figuró en la exposición de París de ese año (cat. 612) con el sugerente título: Isabel la Católica anuncia a Cristóbal Colón que si el tesoro real no es suficiente para pagar los gastos de su expedición está dispuesta a vender sus joyas. Tampoco nos es conocida la actual localización tal vez se encuentre en una colección norteamericana, de otro cuadro, de gran tamaño, 365 × $635 \mathrm{~cm}$, titulado Isabel la Católica cede sus joyas para la empresa de Colón, obra de Antonio Muñoz Degrain (Valencia, 1843 - Málaga, 1924) que fue presentado a la Exposición Nacional de Bellas Artes de 1878, en cuyo catálogo, (cat. 261, pp. 55-56) aparecía con un texto extraído de la Historia General de España, de E. Zamora y Caballero, p. 337, que lo apoyaba iconográficamente: «...Cuando los pocos amigos que creían con celo en la teoría de Colón le vieron verdaderamente determinado á abandonar á España, se llenaron de sentimiento, considerando su partida como una pérdida irreparable para la nación. Contábase entre estos Luis de Santangel, que determinó hacer un osado esfuerzo para impedir el mal si era posible. Obtuvo inmediatamente audiencia de la Reina, acompañado de Alfonso de Quintanilla que le ayudaba ardientemente en todas sus pretensiones. La perentoriedad del caso le dió audacia y elocuencia... La Marquesa de Moya se valió también de su elocuencia para persuadir a la Reina. El generoso ánimo de Isabel se inflamó al fin, como si la empresa hubiera entonces aparecido por primera vez en su mente en el verdadero punto de vista y pronunció su resolución de protegerla. Todavía hubo un momento de duda. El Rey miraba con frialdad aquella negociación, y el Tesoro real estaba absolutamente agotado por la guerra. Se necesitaba tiempo para llenarlo ¿Como podía la Reina girar sobre una caja vacía para medidas á que su esposo se manifestaba contrario? Santangel observaba esta suspensión con trémula ansiedad. Pero no le duró mas que un momento. Con entusiasmo 
digno de ella misma y de la causa que patrocinaba, exclamó Isabel: Yo entro en la empresa por mi Corona de Castilla, y empeñaré mis joyas para levantar los fondos necesarios». Un boceto de este cuadro, de 39 x $66 \mathrm{~cm}$ se conserva en el Museo de Bellas Artes de San Pío V de Valencia.

En un interior rícamente decorado, con tapices recubriendo sus muros, aparece la reina Isabel centrando la composición, de pie, en actitud de dirigirse a Santángel y Quintanilla que se encuentran en el ángulo izquierdo mientras que señala el bargueño, en el centro, donde se encuentran sus joyas. Junto a la reina, la marquesa de Moya. En el lado derecho de la escena el rey Fernando, sedente bajo un dosel y en actitud de escribir y a su lado, eclesiásticos y damas de la corte.

Francisco Jover Casanova también plasmará esta escena en un lienzo titulado Isabel la Católica vendiendo sus joyas para la empresa de Colón, de 64,5 x $105 \mathrm{~cm}$ que fue subastado por la Galería Sothebys de Madrid, el día 26 de junio de 1986. En un interior, con grandes ventanales de tracerías góticas, aparece en el centro la reina Isabel, sedente en un trono gótico, junto a una mesa en la que se encuentran sus joyas. $\mathrm{Al}$ otro lado de la mesa, Santángel y Quintanilla y una dama, apoyada en el ventanal, que mira al espectador. Junto a la reina, un personaje masculino, tal vez el rey Fernando, otro noble y un cardenal.

Posiblemente sea un boceto para este obra una pintura sobre tabla, de Jover (27 x $38 \mathrm{~cm}$ ), con notables variantes, en colección particular levantina. En este caso la escena se desarrolla en una estancia mas reducida, que se ilumina por un ventanal abierto en el lado derecho de la composición. La reina está sentada en el centro y delante de ella aparece un joven y una dama. A la derecha, sobre una mesa una serie de joyas y objetos preciosos y a su lado otros personajes. Junto a la reina, un arca con las joyas y las figuras del rey Fernando, de un cardenal y de otro noble.

En relación con esta «cesión» de las joyas de Isabel la Católica, nos ocupamos ahora de un boceto, hasta ahora desconocido, del pintor Luis García Sampedro (Barcelona, último tercio del siglo XIX y primeras décadas del XX), fechado en 1891, que representa un interior palaciego, en el que el rey Fernando el Católico, sentado en un trono en el que aparecen las armas de Aragón, entrega el dinero de la corona para la empresa americana, que dos criados sacan de un arcón abierto que aparece al lado del monarca. Enfrente del rey, dos personajes de la corte, uno de ellos, posiblemente el tesorero Luis de Santangel. Esta pintura, sobre tablés, de 29,5 x 49,5 cm, en colección particular, viene a plasmar gráficamente 
un recurrente dicho aragonés: «Con dinero de Aragón, nuevo mundo halló Colón para Castilla y León».

El tercer momento que podemos precisar en la iconografía que relaciona a Colón con los Reyes Católicos se concreta en un cuadro de Antonio Muñoz Degrain, titulado Isabel la Católica orando por la empresa de Colón, también citado como Isabel la Católica orando en la colegiata de Taverna, en colección particular (198 x $134 \mathrm{~cm})$, que figuró en la Exposición Nacional de Bellas Artes de 1892 (cat. 828, p. 128). En el interior de un templo de trazas románicas, aparece la reina Isabel, arrodillada, en oración delante de una imagen de la Virgen colocada sobre una ménsula en el muro. Detrás de la soberana, una serie de figuras arrodilladas y un heraldo con maza, junto a la puerta. Hay que destacar en esta obra los numerosos detalles decorativos como las flores esparcidas por el suelo, en las columnas o sobre los capiteles y la riqueza del mueble en el que se apoya la reina.

$\mathrm{Al}$ regreso de Colón a España, tras el Descubrimiento, tendrá lugar el cuarto momento de esta iconografía colombina, el recibimiento de Colón por los Reyes Católicos en Barcelona. La primera pintura que conocemos corresponde al pintor Andrés Crua (Antella, Valencia, 1780 - 1823), fue pintada en 1804 y se titula Colón ante los Reyes Católicos a su regreso de América $(83$ x $134 \mathrm{~cm})$. Se conserva en el Museo de Bellas Artes de San Pío V de Valencia y se encuadra en la serie de temas de historia de España propuesto para los concursos convocados por las Reales Academias. En un amplio interior palaciego, los reyes aparecen sentados en sus tronos rodeados de nobles y cortesanos, y delante de ellos, sentado también en un sillón, Colón, con armadura militar y bastón de mando, rodeado por indios que ofrecen a los monarcas una serie de presentes traídos de las Indias.

Mayor espectacularidad reviste otro lienzo, de Francisco García Ibáñez (Madrid, 1825 - ?), titulado Colón recibido por los Reyes Católicos en Barcelona a la vuelta de su primer viaje, de $111 \times 144 \mathrm{~cm}$, que figuró en la Exposición Nacional de Bellas Artes de 1858 (cat. 56). Se encuentra desde 1941 depositado por el Museo del Prado en el Museo del Ejército. La escena se desarrolla en un exterior, en una idealizada ciudad de Barcelona, con grandes arquitecturas y las carabelas al fondo de la composición. El encuentro con los Reyes tiene lugar a la derecha, delante de una arquitectura palaciega donde aparecen los monarcas bajo un elevado dosel, rodeados de personajes cortesanos, y Cristóbal Colón, de rodillas, ante ellos. En los primeros términos aparecen los indios que han acom- 
pañado a Colón a su regreso y una gran multitud de personajes que son testigos del encuentro.

Esta misma escena transcurre en un interior en la obra de Ricardo Ankerman y Riera (Palma de Mallorca, 1842 - 1907), titulada Presentación de Cristóbal Colón a los Reyes Católicos en Barcelona, óleo sobre lienzo, pintado hacia 1892, en la actualidad en paradero desconocido, con el que su autor alcanzó en 1892 el primer accésit del Certamen Artístico de La Ilustración Española y Americana. En un amplio salón, con ventanales góticos, Cristóbal Colón besa la mano de la reina católica quien, junto con su marido, se encuentra de pie, delante del trono, bajo un amplio dosel. Alrededor de los monarcas aparecen una serie de nobles y cortesanos y detrás de Colón numerosos indios que comienzan también a rendir pleitesía a los monarcas cristianos (Fig. 5).

Otros pintores tomaron también esta página de la historia colombina como argumento para sus obras, y entre ellos debemos mencionar a Valentín Carderera Solano (Huesca, 1796 - Madrid, 1880) quien pintó hacia 1835 para la Reina Regente el lienzo Colón ante los Reyes Católicos al regresar de América; Ricardo Villegas Cordero, que ejecutó la pintura Colón ante los Reyes Católicos después de regresar de América, en paradero desconocido; José María Rodríguez de Losada, autor de un cuadro titulado Colón recibido por los Reyes Católicos a su regreso de América $(118 \times 168 \mathrm{~cm})$ en paradero desconocido y Francisco Domingo Marqués (Valencia, 1842 - Madrid, 1920) que hacia 1884 trabajaba en París en un cuadro que le había encargado el Senado y que representaba a Colón en Barcelona de regreso del Nuevo Mundo, que desconocemos si lo concluyó.

Tras el recibimiento y la entrega de los presentes traídos desde América, expuso Colón ante los reyes las peripecias de su largo viaje, momento este que plasma José Arpa y Perea (Carmona, Sevilla, 1860 - Sevilla, 1952) en el boceto titulado La llegada de Colón a Barcelona, en el momento de hacer la narración de su viaje delante de los Reyes y de la Corte, pintado en Roma en 1883 y del que ignoramos si llegó a ejecutar la versión definitiva. También queremos destacar en este mismo sentido el lienzo de Ricardo Balaca y Orejas-Canseco (Lisboa, 1844 - Aravaca, Madrid, 1880), Recepción de Colón por los Reyes Católicos al regresar de su primer viaje, también conocido como Colón recibido por los Reyes Católicos al regresar de su primer viaje a América, en paradero desconocido. En un interior los Reyes Católicos sedentes en sus tronos, bajo dosel, a cuyos lados se encuentran dos heraldos con mazas, y acompañados de la 


\section{Los Reyes Católicos en la pintura española del siglo XIX}

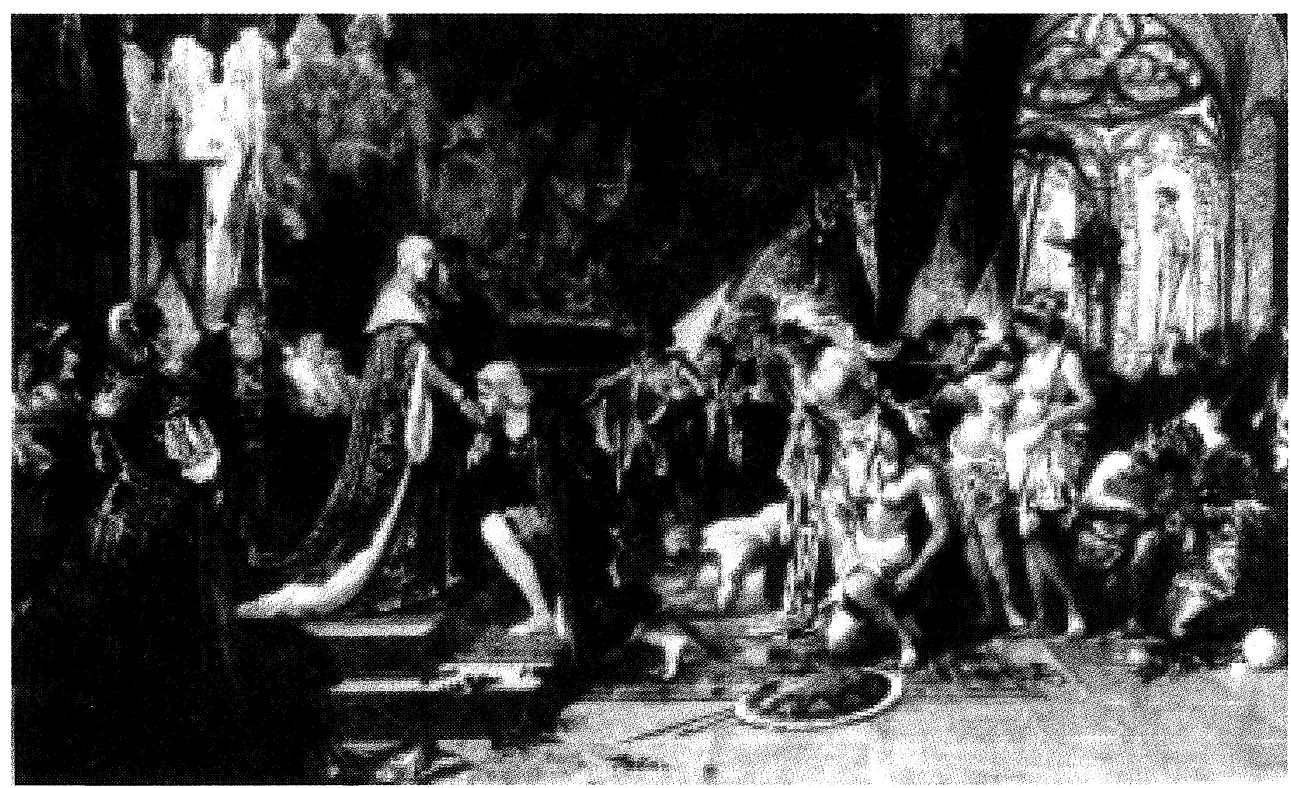

Fig. 5. Ricardo Ankerman, Presentación de Cristobal Colón a los Reyes Católicos en Barcelona, paradero desconocido.

corte, escuchan a Colón que se sitúa frente a ellos, junto a un grupo de indios y narra las peripecias y el éxito del viaje.

El último momento que encontramos en la iconografía que comparten Cristóbal Colón y los Reyes Católicos corresponde a la Reposición de Colón, momento que plasmó el pintor Francisco Jover Casanova en el lienzo de este título, de 331 x $473 \mathrm{~cm}$, fechado en 1881 y que se encuentra depositado por el Museo del Prado en la Universidad de Valladolid. Figuró en la Exposición Nacional de Bellas Artes de 1881 y en el catálogo de la muestra, aparece el siguiente texto de la Historia de los Reyes Católicos, de Prescott: «Colón, con estas seguridades de la disposición favorable hacia él por parte de sus reyes, partió sin dilación hacia Granada, á donde llegó el 17 de Agosto del mismo año de 1500. En cuanto se presentó tuvo entrada á la presencia real; y Doña Isabel, no pudiendo reprimir sus lágrimas al respecto del hombre cuyos ilustres servicios habían sido tan indignamente recompensados bajo el manto, digámoslo así, de su propia autoridad, procuró calmar su lacerado corazón dándole las más vivas y señaladas muestras de afecto y del pesar que sus infortunios le causaban, desde el primer momento de su desgracia, habia confiado en la rectitud y bondad de Doña Isabel; porque como observa un antiguo escritor castellano, ésta le había favorecido siempre mucho más que su marido, prote- 
giendo sus intereses y dándole muestras de especial afecto y benevolencia; y cuando ahora vió la emoción que á su real señora conmovia, y escuchó sus palabras de consuelo, quedóse completamente satisfecho su honrado y generoso corazón; y arrojándose a sus plantas, dejóse arrastrar de los sentimientos que le dominaban y lloró» (Cat. 310, pp. 64-65).

Jover interpreta la escena siguiendo el texto propuesto, y así enmarca la escena en un amplio salón, de arquitectura árabe, decorado con un tapiz, desarrollándose en el centro, sobre una alfombra, el momento cumbre del encuentro entre los Reyes Católicos y Cristóbal Colón. Los monarcas se han levantado de sus tronos, que aparecen vacíos sobre ellos y la reina Isabel se inclina para levantar a Colón que aparece arrodillado a sus pies. Todo ello ante la atenta mirada del rey Fernando, y de damas, eclesiásticos y nobles que en distintos grupos, completan la escena.

\section{Testamento y muerte de Isabel la Católica}

Los últimos años de la vida de la reina Isabel fueron amargos. La infanta doña Isabel, su primogénita, casada en 1490 con el príncipe Alfonso de Portugal, había enviudado pocos meses más tarde y hacia vida retirada, casi de monja, cuando fue requerida en matrimonio por su cuñado el Rey Manuel, con el que casó en septiembre de 1497, muriendo al año siguiente al dar a luz a su hijo Miguel.

En 1496 se había celebrado una doble boda: la del príncipe don Juan con Margarita de Austria y la de la infanta doña Juana con Felipe el Hermoso. El rey Fernando veía en ella una combinación política mientras mientras que Isabel, la promesa de una sucesión asegurada. Sin embargo, las desgracias vinieron seguidas pues en octubre de 1497 moría el príncipe don Juan y solamente quedaba un vástago varón de su sangre, Miguel, que murió en 1500, representando para la reina un duro golpe. Para heredar la corona tan sólo quedaban doña Juana y don Felipe el Hermoso, pero la princesa comenzaba a padecer ataques de locura.

Estos sucesos contribuyeron poco a poco a destruir la muy minada su salud de la reina doña Isabel, quien el día 12 de octubre de 1504 dictaba su testamento y poco después el 3 de noviembre agregaba un codicilo de últimas voluntades.

Eduardo Rosales presentó a la Exposición Nacional de Bellas Artes de 1864 el cuadro titulado Isabel la Católica dictando su testamento, óleo so- 
bre lienzo, de 290 × $400 \mathrm{~cm}$, pintado en Roma, con el que ganó la primera medalla. Este cuadro, que se conserva en el Museo del Prado, alcanzó pronto una elevadísima cota de popularidad, y a propósito de esta pintura, afirma Reyero que de ninguna de las otras pinturas de historia que recoge en su exhaustivo repertorio «se ha escrito, desde entonces, tanto como sobre el Testamento; ninguna tiene la documentación ni ha merecido el interés unánime de la historiografía artística; ninguna se ha reproducido tanto; ninguna ha recibido el aplauso del público, de los antiguos y de los modernos, con tan desusada coincidencia. Por todo ello resulta difícil sustraerse de la jerarquización que ha impuesto la pintura de Rosales. Se trata, sin duda alguna, de una obra capital, tanto para el estudio, como para la valoración de la pintura de historia...» ${ }^{15}$.

En el interior del dormitorio de la reina, aparece doña Isabel en el lecho, con dosel y cortinajes, que se dirige el escribano que escribe sobre un pupitre. La actitud de la reina queda reforzada por su mano derecha extendida hacia el escribano. A la derecha de la composición un grupo de cuatro personas, una de ellas el cardenal Cisneros, mientras que a la izquierda está sedente el rey Fernando y a su lado, de pie, Beatriz Galindo. Al otro lado de la cama, las dos figuras que allí encontramos se han identificado con los marqueses de Moya ${ }^{16}$ (Fig. 6).

Tras el fallecimiento de doña Isabel en el castillo de la Mota en Medina del Campo, su cadáver fue trasladado hasta Granada y éste es el momento elegido por Salvador Viniegra (Cádiz, 1862 - Madrid, 1915) para el cuadro titulado Entierro de Isabel la Católica, pintado en Cádiz en 1885 y que se conserva en el Alcázar de Segovia. De este obra se ha destacada la innegable relación que presenta con el cuadro de Doña Juana la Loca de Pradilla, que en 1878 había alcanzado la primera medalla de honor de las Exposiciones Nacionales de Bellas Artes. El traslado del cuerpo de la soberana se hizo en el mes de diciembre de 1504, y así vemos transitar por los campos de Castilla a los cuatro portadores del féretro, vestidos de blanco, con capuchas y velas y junto a ellos, otros cuadro personajes, del relevo, igualmente vestidos y un grupo de personajes a caballo, que se pierde en el infinito, entre los que aparece, en primer lugar, un eclesiástico que se identifica con el cardenal Cisneros. Los árboles y las lanzas de los últimos planos potencian la verticalidad del cuadro, calificado como «una de las más sorprendentes pinturas del género, imbuida de realismo formal y de una visión fantasmagórica y sobrecogedora del pasado, de esa España que veía pasar por sus barrizales los cadáveres de sus monarcas» ${ }^{17}$. 


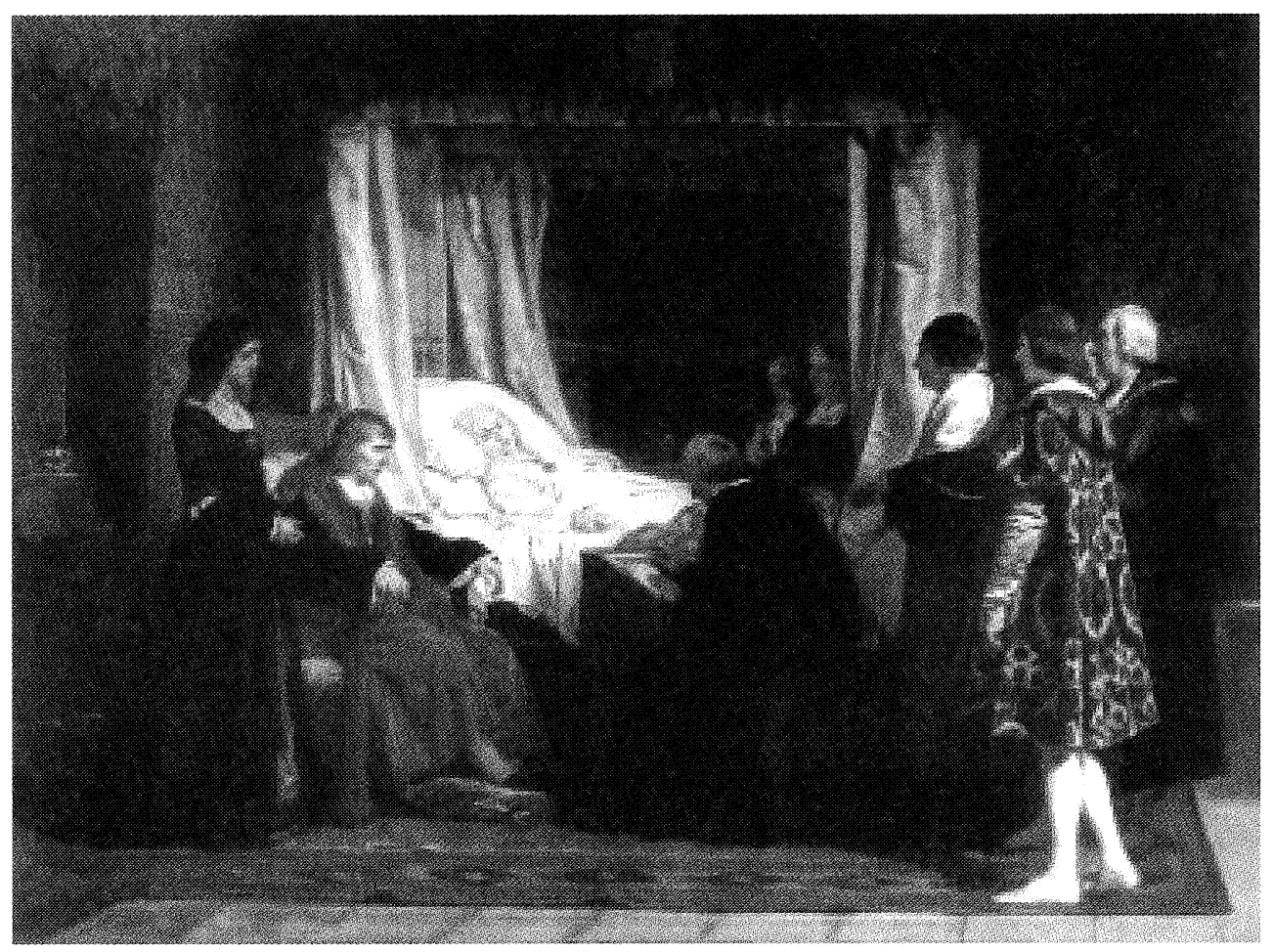

Fig. 6. Eduardo Rosales, Isabel la Católica dictando su testamento, Madrid, Museo del Prado.

\section{Otros temas de Fernando el Católico}

Son escasos los cuadros que narran escenas de la vida del rey Fernando el Católico en solitario, sin relación con la reina Isabel, por lo que tienen un notable interés algunas a las que brevemente nos referimos.

Muerta la reina doña Isabel, don Fernando, para evitar el peligro que para él representaba en Castilla, Milán y Nápoles el Tratado de Blois, firmado el 22 de septiembre de 1504 entre Luis XII y Felipe el Hermoso, por el que se concertaba el matrimonio de Claudia, hija del monarca francés con el archiduque Carlos, luego Carlos I, contrajo nuevo matrimonio el 19 de octubre de 1505 con doña Germana de Foix, hija de Juan Gastón de Foix, conde de Etampes y vizconde de Narbona y de María de Orleans, hermana del rey Luis XII de Francia. Cuando doña Juana y don Felipe el Hermoso llegaron a Castilla, abandonaron don Fernando y doña Ger- 
mana el reino, embarcándose en Barcelona el 4 de septiembre de 1506 rumbo a Nápoles, ciudad en la que entraron solemnemente el día 1 de noviembre. Será algunos meses más tarde, cuando muerto Felipe el Hermoso el 25 de septiembre de 1506, regresaron don Fernando el Católico y doña Germana, desembarcando en el puerto del Grao en Valencia el día 21 de julio de 1507, quedando la reina con el cargo de lugarteniente general del Reino. Este es el argumento de un cuadro de José Ribelles (Valencia, 1778 - Madrid, 1835) es el cuadro titulado Desembarco en el Grao de Fernando el Católico y Germana de Foix, también conocido como Regreso de Nápoles a España de los Reyes Fernando el Católico y Germana de Foix que se conserva en el Museo de Valencia.

Vicente Palmaroli pintó un cuadro titulado Entrevista de Don Fernando y Doña Juana en Tórtoles, en colección particular, encuentro que tuvo lugar el día 29 de agosto de 1507 y en el que la reina Juana delegó en su padre todo su poder. De este momento se ocupa el cronista Pedro Mártir de Anglería en su Epistolario en carta escrita el día 5 de septiembre de 1507 en Santa María del Campo al conde de Tendilla: «La respetuosa hija, tu Reina Juana, cayó en brazos de su padre el día 29 de agosto, en el pueblo de Tórtoles. Por la alegría, el Rey no pudo contener las lágrimas. La Reina aunque permaneció inmóvil, pues no sabe lo que es el llanto, desde que tuvo el inconmensurable dolor de descubrir en Flandes a la amante de su esposo abrió, sin embargo, un poco su alma en estos instantes de alegría. Estuvieron conversando hasta muy avanzada la noche y forcejearon sobre cuál de los dos había de elegir el lugar a donde con más comodidad fuera trasladada la corte...» ${ }^{18}$.

Otra visita del rey Fernando a su hija, en este caso en el palacio de Tordesillas en 1509, fue plasmada por Pradilla en un lienzo, en colección particular, de $36 \times 62 \mathrm{~cm}$. La escena se desarrolla en un interior gótico, salón palaciego en cuyo ángulo izquierdo arde un brillante fuego de hogar; a su lado, el rey Fernando y junto a él el cardenal Cisneros. La reina doña Juana, acompañada de dos damas de su corte aparece sentada en el lado derecho de la composición ${ }^{19}$.

Por último recordaremos otro lienzo que representa la muerte de Fernando el Católico que tuvo lugar en Madrigalejo (Cáceres) el 25 de enero de 1516. Titulado La muerte del Católico, está en paradero desconocido y fue presentado por su autor el pintor Ricardo López Requeni (Valencia, ? - Játiva, 1869) en la Exposición Nacional de Bellas Artes de 1864 (cat. 216, p. 41). 


\section{Retratos}

Para concluir esta aproximación iconográfica a los Reyes Católicos en la pintura española del siglo XIX, queremos recoger algunos retratos de los monarcas. Una pareja de ellos, de iguales dimensiones $(225 \times 141 \mathrm{~cm})$ se encuentran depositados por el Museo del Prado desde 1988 en el Alcázar de Segovia. El del la reina fue pintado por Luis de Madrazo mientras que el del rey don Fernando se le encargó al pintor aragonés Bernardino Montañés. La descripción de los mismos, en el Inventario General del Museo del Prado, en el volumen correspondiente a la colección real es la siguiente: « $\mathrm{D}^{\mathrm{a}}$ Isabel la Catolica, vestido carmesí y la mano derecha sobre un libro colocado en una mesa con tapete azul, y en la izquierda el cetro» y «D.n Fernando 5..$^{\circ}$ el Catolico; los guantes en la mano izquierda apoyada en una mesa con tapete carmesí, y en la derecha el cetro» ${ }^{20}$.

Por último mencionaremos otro retrato de Fernando el Católico, pintado por Manuel Aguirre Monsalve (Málaga, 1822 - Borja, Zaragoza, 1856) en 1853, de 212 × $124 \mathrm{~cm}$, que se conserva en la colección de la Diputación de Zaragoza.

\section{Notas}

1 VV.AA.: Historia y alegoría: los concursos de pintura de la Real Academia de Bellas Artes de San Fernando (1753-1808), Real Academia de Bellas Artes de San Fernando, Madrid, 1994, pp. 175-178. Es interesante también el articulo de Pérez Sánchez, Alfonso E.: «Pintar la historia», en el catálogo La pintura de historia del siglo XIX en España, de la exposición celebrada por el Museo del Prado en las salas del antiguo Museo Español de Arte Contemporáneo, Madrid, octubre-diciembre de 1992, pp. 17-35.

2 Paéz Ríos, Elena: Repertorio de grabados españoles en la Biblioteca Nacional, Ministerio de Cultura, Dirección General de Bellas Artes, Archivos y Bibliotecas, Secretaría General Técnica, Madrid, 1981, Tomo I, p. 40, ilust. 102.

3 Sobre la pintura de historia, ver: Reyero, Carlos: Imagen histórica de España (1850-1900), Espasa Arte, Espasa-Calpe, S. A., Madrid, 1987 con amplia bibliografía; Reyero, Carlos: «Los temas históricos en la pintura española del siglo XIX», en el catálogo La pintura de historia del siglo XIX en España, de la exposición celebrada por el Museo del Prado en las salas del antiguo Museo Español de Arte Contemporáneo, Madrid, octubre-diciembre de 1992, pp. 37-68 y Diez, José Luis: «Evolución de la pintura española de historia en el siglo XIX", también en el mismo catálogo ya mencionado en esta obra, pp. 69-101. Es interesante el artículo de Camón Aznar, José: «Pintura de Historia», publicado en ABC, Madrid, 13 de enero de 1957 y recogido en Las artes y los días, Editorial Sucesores de Rivadeneyra, S. A., Madrid, 1965, pp. 291-293.

4 Mendoza, 1870, p. 31

5 Díez, 1992, cat. 7, pp. 154-159, cit, p. 156. 


\section{Los Reyes Católicos en la pintura española del siglo XIX}

6 VV.AA.: Historia y alegoría, 1994, pp. 114-117.

7 Colmenares, Diego de: Historia de la insigne ciudad de Segovia y Compendio de las Historias de Castilla, Segovia, 1637, cap. XXIII, XV, fol. 413. La presencia de Fernando de Aragón en esta secuencia de la historia parece forzada pues si el Tratado de lo Toros de Guisando tuvo lugar el 14 de septiembre de 1468 y la entrada triunfal de doña Isabel en Segovia fue como consecuencia de este Tratado, no puede aparecer el príncipe aragonés, con quien la reina no contrajo matrimonio hasta el día 19 de octubre de 1469.

8 García Loranca; Ana y García Rama, J. Ramón: Pintores del siglo XIX. Aragón, La Rioja, Guadalajara, IberCaja, Zaragoza, 1992, p. 448.

9 Rincón García, Wifredo: Francisco Pradilla, Aneto Publicaciones, Zaragoza, 1999, pp. 93-129 y cat. 78 , pp. 304-307.

10 Sobre este tema ver: Arias Anglés, Enrique y Rincón García, Wifredo: «La imagen del Descubrimiento de América en la pintura de historia española del siglo XIX», VV. AA.: Relaciones artísticas entre España y América, Departamento de Historia del Arte «Diego Velázquez», Centro de Estudios Históricos, Consejo Superior de Investigaciones Científicas, Madrid, 1990, pp. 273-364.

11 Catálogo Exposición de la Obra de EduardoRosales (1836-1873), Patronato Nacional de Museos, Madrid, 1973, cat. 81, pp. 110-111.

12 Reyero, 1987, p. 280.

13 Reyero, 1987, p. 277.

14 Rincón, 1999, cat. 18 , p. 280.

15 Reyero, 1987, p. 238.

16 Reyero, 1987, pp. 239-240 dedica un amplio estudio a esta obra, recogiendo los comentarios que sobre la misma han hecho distintos autores. También ver el exhaustivo trabajo de Díez, 1992, pp. 212-229.

17 Reyero, 1987, p. 241.

18 Anglería, Pedro Mártir de: Epistolario, Madrid, 1953, Tomo X, carta 359, pp. 208209.

19 Rincón, 1999, cat. 748, p. 512.

20 Museo del Prado. Inventario General de Pinturas. I. La colección real, Museo del Prado-Espasa Calpe, Madrid, 1990, núms. 2943 y 2944, p. 770. 


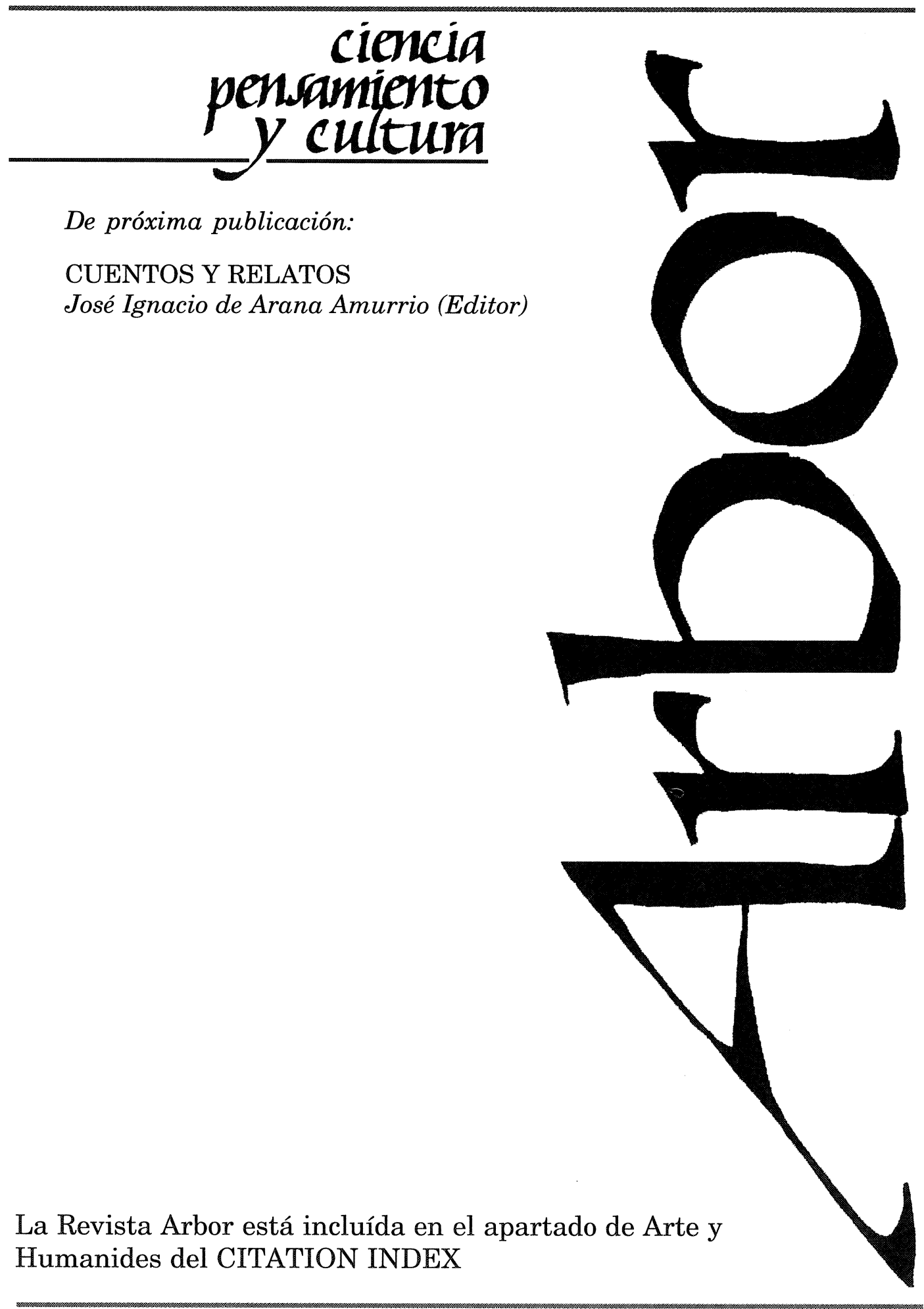

La Revista Arbor está incluída en el apartado de Arte y Humanides del CITATION INDEX 